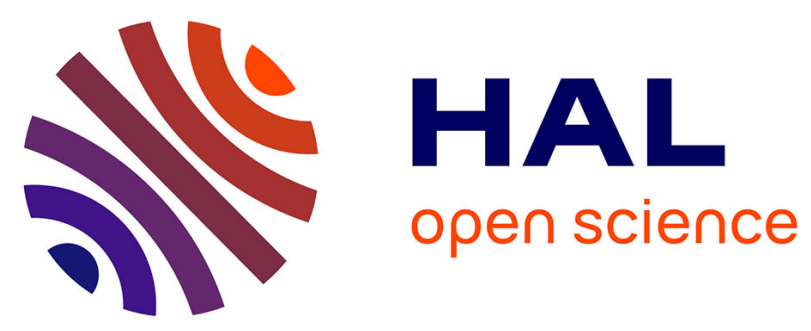

\title{
A new methodology for concrete resistivity assessment using the instantaneous polarization response of its metal reinforcement framework
}

\author{
Gabriel Samson, Fabrice Deby, Jean-Luc Garciaz, Jean Louis Perrin
}

\section{- To cite this version:}

Gabriel Samson, Fabrice Deby, Jean-Luc Garciaz, Jean Louis Perrin. A new methodology for concrete resistivity assessment using the instantaneous polarization response of its metal reinforcement framework. Construction and Building Materials, 2018, 187, pp.531-544. 10.1016/j.conbuildmat.2018.07.158 . hal-01990082

\section{HAL Id: hal-01990082 \\ https://hal.science/hal-01990082}

Submitted on 12 Jun 2019

HAL is a multi-disciplinary open access archive for the deposit and dissemination of scientific research documents, whether they are published or not. The documents may come from teaching and research institutions in France or abroad, or from public or private research centers.
L'archive ouverte pluridisciplinaire HAL, est destinée au dépôt et à la diffusion de documents scientifiques de niveau recherche, publiés ou non, émanant des établissements d'enseignement et de recherche français ou étrangers, des laboratoires publics ou privés. 


\title{
A new methodology for concrete resistivity assessment using the instantaneous polarization response of its metal reinforcement framework
}

Gabriel Samson ${ }^{1, *}$, Fabrice Deby ${ }^{1}$, Jean-Luc Garciaz ${ }^{2}$, Jean-Louis Perrin ${ }^{2}$

${ }^{1}$ LMDC, INSAT/UPS Génie Civil, 135 Avenue de Rangueil, 31077 Toulouse cedex 04 France.

${ }^{2}$ LERM SETEC, 23 Rue de la Madeleine, 13631 Arles cedex France

\begin{abstract}
A new methodology is developed to assess concrete cover resistivity using the instantaneous response of the polarization of a metal rebar (galvanostatic pulse method). The instantaneous ohmic drop is linked only with the concrete resistance, which depends on the concrete cover and resistivity, and rebar diameter. A numerical model was developed in Comsol Multiphysics ${ }^{\circledR}$ in order to create a graph linking concrete resistivity to concrete resistance for concrete cover ranging between 1 to $160 \mathrm{~mm}$. This graph and the measured ohmic drop can be used to determine concrete resistivity for any rebar diameter/concrete cover configuration. The theory developed numerically was then confirmed using an experimental setup with controlled water resistivity. The theory is then generalized for counter electrode (CE) diameter ranging from 20 to $70 \mathrm{~mm}$. Finally, the study reveals that the graph developed for a single rebar can be used for any rebar framework density.
\end{abstract}

\section{Keywords}

Resistivity, reinforced concrete structures, corrosion, geometrical factor, one-electrode method, rebar spacing 


\section{Highlights}

- A new concrete resistivity assessment methodology is proposed.

- Resistivity is calculated with a reverse calculation based on 3D numerical model.

- The geometrical factor depends on CE diameter, concrete cover and rebar diameter.

- The numerically developed method was experimentally validated in water.

- The geometrical factor does not depend on rebar framework density.

\section{Graphical abstract}
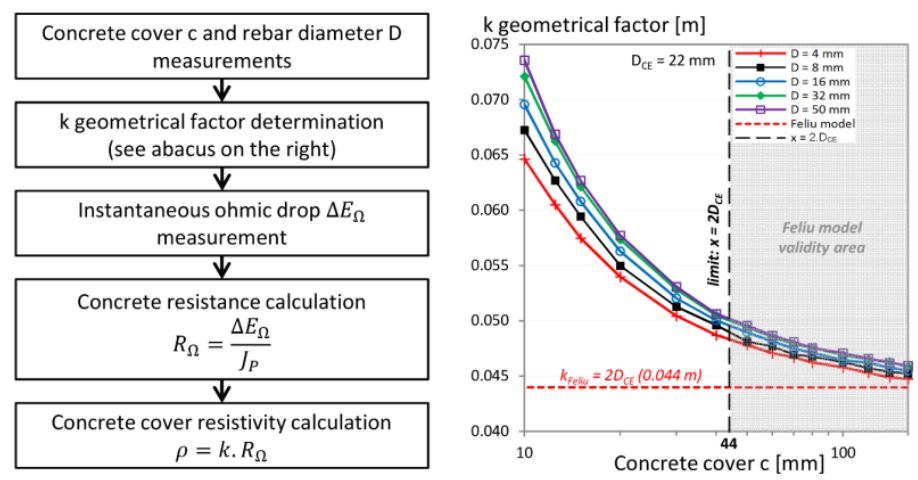

\section{Corresponding author *}

Gabriel Samson: samson@insa-toulouse.fr

\section{Acknowledgements}

DIAMOND is a collaborative R\&D project supported by the French government FUI program, Direction Générale des Entreprises, BPI France and PACA regional council, and accredited by four competitiveness clusters : SAFE, Mer Méditerranée, Nuclear Valley, Alpha RLH. 


\section{Introduction}

The corrosion of steel bars is a major issue in the durability of reinforced concrete structures

[1]. Corrosion initiation and propagation depend on the concrete durability parameters (porosity, diffusivity, absorption, permeability). However, assessing these parameters on-site is time consuming, expensive and/or requires destructive tests. Resistivity is being increasingly considered as a reliable durability index for assessing the long-term performance of concrete structures [2-4].

Electrical resistivity is defined as the resistance against the flow of an electrical current. It is a specific, geometry-independent property of a material. For concrete, it may vary from 10 to $10^{5} \Omega . \mathrm{m}$ [5]. The electrical current is carried by the dissolved ions in the pore solution [6] so resistivity depends on the pore structure, the degree of saturation and the distribution of the ion concentrations in the pore fluid. Concrete resistivity depends on both the concrete production process (water/cement ratio, cement type, mineral admixtures, degree of hydration, curing) and the properties of the concrete in situ (temperature, degree of saturation, ion concentrations in the pore solution) [7]. The latter parameters depend on the production process and the history of external environmental conditions (temperature, relative humidity, air chloride content).

The work presented here is part of the DIAMOND project [8], which aims to create an electrochemical device to assess the corrosion state of reinforced concrete structures by measuring the half-cell corrosion potential $E_{c o r r}$, the concrete resistivity $\rho$, and the corrosion rate $i_{c o r r}$, with the same device. This article focusses on measuring concrete resistivity. The measurement will be performed with a galvanostatic pulse measurement. This technique is employed since around 30 years to determine the corrosion rate of the rebar/concrete interface and the measurement procedure can be found in many papers [9-15]. However, in all these papers, the galvanostatic pulse technique is used to determine the corrosion rate. In these 
studies, the instantaneous ohmic drop measured, linked with the global concrete electric resistance, is subtracted to the potential response in steady-state regime (in a one dimension way - Randles model) to determine the polarization resistance of the concrete rebar interface (and thus calculate the corrosion rate). We propose here to use this instantaneous ohmic drop to determine the concrete cover resistivity more than the only global resistance. The principle of this resistivity measurement technique is based on the approach initiated by Newman [16] and Feliu et al. [17].

The aim here is to overcome the limitations described in Feliu's article and to propose a method that could be used for any rebar diameter/concrete cover configuration that may be found on-site and for a wide range of counter-electrode diameter (from 20 to $70 \mathrm{~mm}$ ).

Our approach is based on a 3D numerical model. The numerically obtained results are used to do a reverse calculation of the resistivity with the instantaneous concrete ohmic resistance measured with the galvanostatic pulse method.

The various existing resistivity measurement techniques are presented first, followed by the newly developed method. The experimental device (DIAMOND probe and experimental validation setup) are introduced. The measurement is modelled numerically using COMSOL software in order to obtain the geometrical factor $k$, linking the concrete resistance $R_{\Omega}$ to the concrete resistivity $\rho$ for all steel bar diameter/concrete cover configurations. The geometrical factor is also calculated for different counter-electrode (CE) diameter and presented in appendix. The theory developed is then confirmed using the experimental setup. Finally, we demonstrated that the model developed on a single rebar can be applied without modifications for a more or less dense rebar framework which is more representative of what is found onsite. 


\section{Theoretical background: resistivity measurement}

There are several resistivity measurement techniques that can be employed. For all of them, the relationship between the resistivity $\rho[\Omega . \mathrm{m}]$ and the measured resistance $R_{\Omega}$ is given in Eq. 1.

$\rho=k R_{\Omega}$ Eq. 1

where $R_{\Omega}[\Omega]$ is the concrete resistance (e.g. ratio between applied current and measured potential drop) and $k[\mathrm{~m}]$ is a geometrical factor that depends on the technique employed and the sample geometry [18]. The two-electrode (or direct) method uses a regular geometry with two electrodes placed face to face (Figure 1 (a)). An alternating current is applied and the potential drop between the electrodes is measured. Usually, a low frequency is employed (from 100 to $1000 \mathrm{~Hz}$ ). The resistivity $\rho[\Omega . \mathrm{m}]$, is then calculated with:

$\rho=\frac{S}{l} R_{\Omega}$

where $S\left[\mathrm{~m}^{2}\right]$ is the cross-sectional area perpendicular to the current and $l[\mathrm{~m}]$ is the height of the prismatic or cylindrical concrete sample. However, on-site, this technique cannot be implemented without destructive coring.

On-site, the method most commonly used for resistivity measurement is the Wenner method (four-point method) [19]. Four electrodes are equally spaced (electrode spacing $a[\mathrm{~m}]$ ) on the concrete surface (Figure 1 (b)). The two outer electrodes apply a alternating current and the difference in potential is measured by the inner electrodes. The measured resistance $R_{\Omega}$ must be converted into resistivity using the following equation:

$\rho=2 \pi a R_{\Omega}$

Eq. 3

The resistivity obtained is usually called the apparent resistivity. Eq. 3 is applied for homogeneous semi-infinite volumes. However, experiments have indicated that sample size and the presence of steel bar(s) can lead to erroneous results [4,20-22] and these aspects have to be considered carefully to obtain the correct resistivity value [7]. Both two-electrode and 
Wenner methods use alternating current in order to prevent the polarization of the metal electrodes.

The one-electrode (or disc-bar) method proposed by Feliu et al. [17] can be employed to measure concrete cover resistivity between a concrete surface and the rebar/concrete interface (Figure 1 (c)). This method is based on the work of Newman [16], who estimated the ohmic drop due to the resistance $R_{\Omega}$ between a small disc (the CE) of diameter $D_{C E}$ placed on the surface of an electrolyte and a large working electrode (WE), placed at infinity (a metal bar). Contrary to the two previous methods, continuous current is employed, in order to polarize the rebar, in steady-state. Theoretically, the electrical resistivity measured between the bar and the $\mathrm{CE}$ is:

$\rho=2 D_{C E} R_{\Omega}$

Eq. 4

This relation is theoretically verified only if the metal surface bar area is much greater than the disc area [16]. According to Feliu, in practice, this method can be applied to measure concrete resistivity if the cover thickness is greater than about twice the diameter of the disc being use as the CE [17]. Thus, this method cannot be employed for concrete cover smaller than two CE diameter. The fact that an electrical connection to the steel bar is required explains why this method is hardly ever used for resistivity measurements on-site. However, corrosion rate assessment also requires a connection between the CE and the steel bar [915,23,24]. Using the same device to simultaneously measure concrete resistivity and corrosion rate could help in the evaluation of the corrosion state of a reinforced concrete structure. 

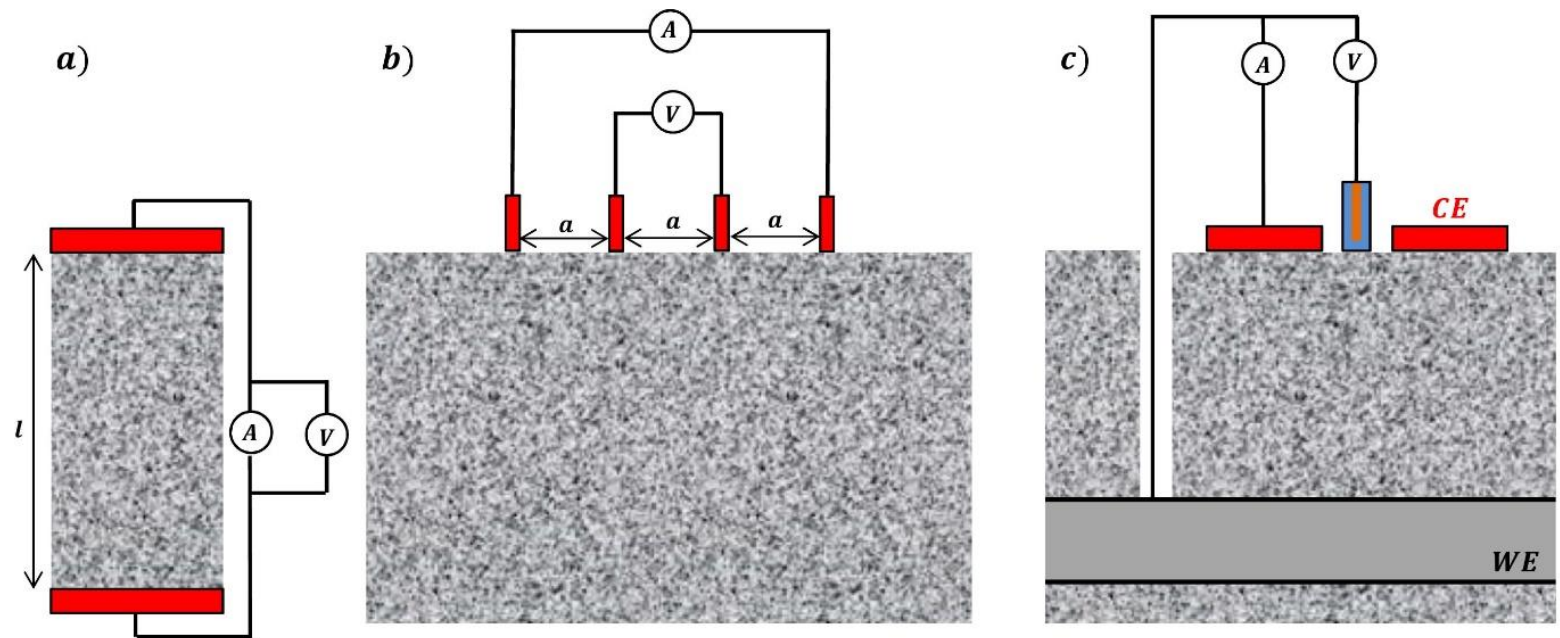

Figure 1. Principles of resistivity measurements. Two-electrode method (a); Wenner probe (b); one-electrode method (c).

\section{General measurement principle}

For the one-electrode method, an electrical connection is made to the rebar. The rebar diameter $D[\mathrm{~m}]$ and concrete cover thickness $c[\mathrm{~m}]$ can be accurately evaluated by using a non-destructive system such as a pachometer or ground penetrating radar [25].

An equivalent electrical circuit is presented in Figure 2 (a). The rebar/concrete interface can be modelled by a Randles equivalent circuit [9], which associates the polarization resistance $R_{P}$ and the capacitance $C$. Concrete resistance is $R_{\Omega}$. The polarization of the rebar is a transient phenomenon. This one-dimensional representation is only qualitative because, in reality, the three-dimensional nature of the problem should be taken into account.

A reference electrode (RE) is used to measure the potential on the surface. The reference potential $E_{r e f}$ of the RE is the difference between the absolute potential $\varphi_{m, \text { ref }}$ of the metal used in the probe and its surrounding solution $\varphi_{\text {sol,ref. }}$ The reference potential $E_{\text {ref }}$ remains constant; this is why this type of potential measurement electrode is called "reference". In practice, an electrically conductive material (conductive gel) is placed between the concrete surface and the probe to ensure a good electrical contact (constant potential) between the concrete surface and the surrounding solution inside the probe. The absolute potential in the solution 
surrounding the $\operatorname{RE} \varphi_{\text {sol, ref }}$ is then equal to the absolute potential of the concrete at the surface $\varphi_{c, s u r f}$ The corrosion potential $E_{c o r r}$ (half-cell rebar/concrete) is the difference between the metal rebar absolute potential $\varphi_{m}$ and the surrounding concrete absolute potential $\varphi_{c}$.

The evolution of absolute potential in the system without polarization $\left(J_{P}=0\right)$ is presented on the schematic layout of Figure 2 (b). Without polarization, there is no current flowing through the concrete. The absolute potential in the concrete remains constant $\left(\varphi_{c, \text { surf }}=\varphi_{c}\right)$. The measured potential $E_{m e s}$ is then equal to $E_{c o r r}-E_{r e f}$. The corrosion risk can thus be established according to the corrosion potential value obtained [1].
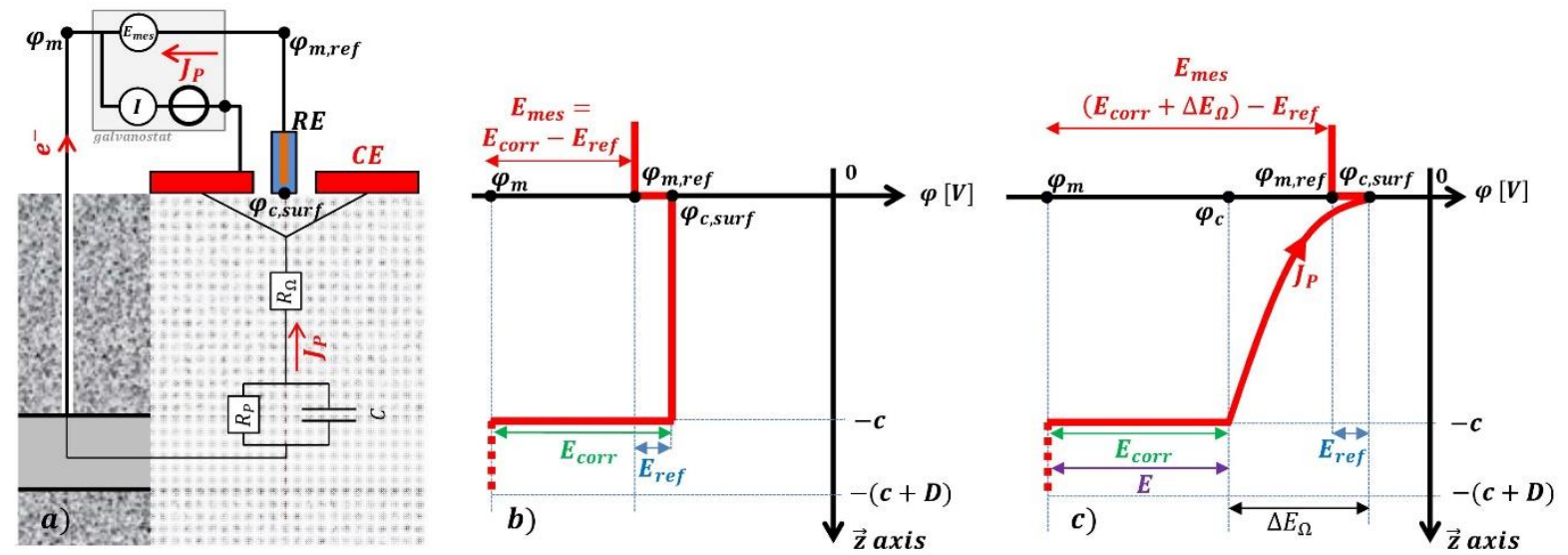

Figure 2. Equivalent electrical circuit (a), absolute potential evolution without polarization (b), with polarization, $\mathrm{t}=\mathbf{0}(\mathrm{c})$.

With current injection, in the steady-state, the relation between half-cell potential $E$ and the current density at the rebar/concrete interface is governed by the Butler-Volmer equation [26]. However, the resistivity measurement technique proposed in this article is based on the instantaneous response of the system. The absolute potential evolution at the beginning of the polarization is presented in Figure 2 (c). At this moment, the capacitance acts as a short-cut. The half-cell potential $E$ remains equal to the corrosion potential $E_{c o r r}$. Thus, the measured instantaneous ohmic drop $\Delta E_{\Omega}$ depends only on the injected current $J_{P}$ and concrete resistance $R_{\Omega}$, which mostly depends on the concrete resistivity $\rho$ and the concrete thickness, $c[\mathrm{~m}]$ : 
The fact that the rebar is active or passive (or locally active) does not change the instantaneous ohmic drop. It means that this method is particularly interesting when the rebar is locally active and the measurement of the polarization resistance cannot be performed $[27,28]$.

\section{$4 \quad$ Materials and experimental setup}

\subsection{DIAMOND probe}

The schematic layout of the DIAMOND probe is presented in Figure 3. The potential at the concrete surface is measured on the centre of the probe, on a small circular surface (5 mm diameter) with a $\mathrm{Cu} / \mathrm{CuSO}_{4} \mathrm{RE}$. The $\mathrm{CE}$ has a ring shape with $8 \mathrm{~mm}$ internal diameter and $22 \mathrm{~mm}$ external diameter (Figure 3). This device is simpler (no guard ring) compared to the commercials devices (i.e. GECOR and GalvaPulse) usually employed to determine rebar corrosion rate. Guard rings are usually associated with confinement problems $[12,29,30]$. The continuous injected current $J_{P}$ is controlled by a galvanostat developed in our laboratory. It was calibrated with an Iso-tech multimeter. A photo of the probe is also presented in Figure 3.
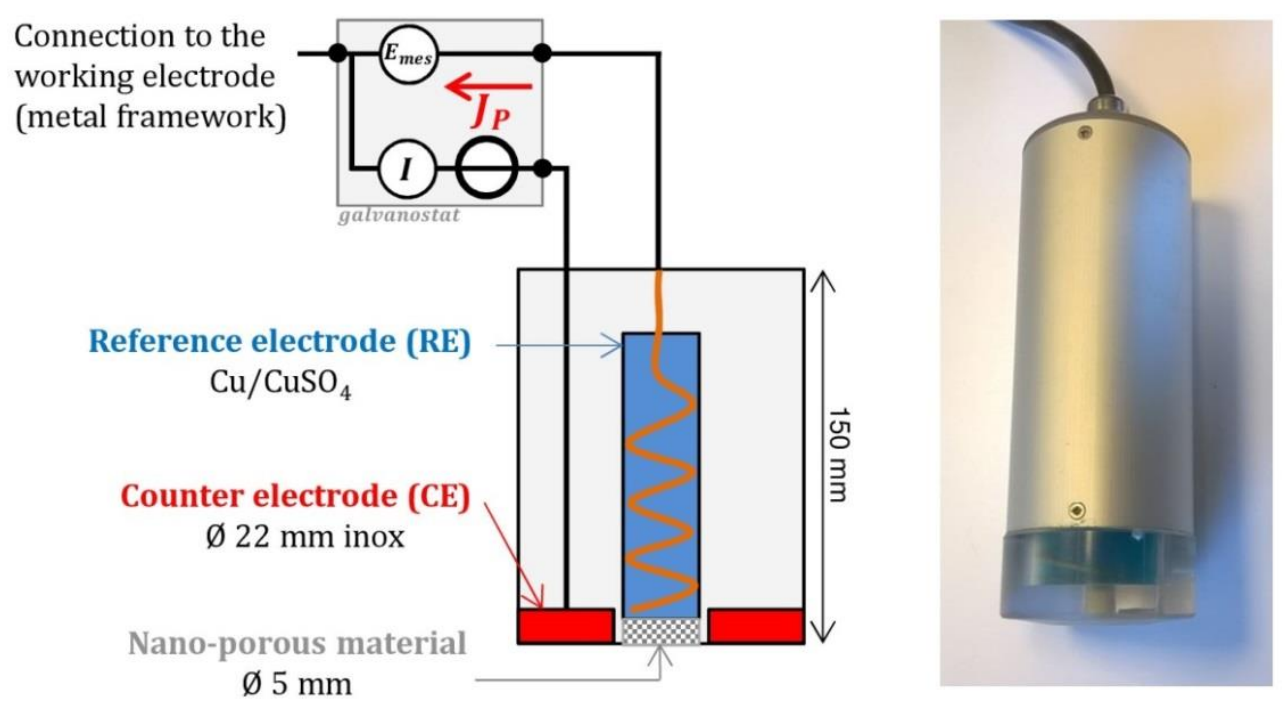

Figure 3. DIAMOND probe: schematic layout and side view photo. 


\subsection{Geometry of experimental validation setup}

We developed a simple setup to validate our model on water (Figure 4). A container (350 mm long, $250 \mathrm{~mm}$ wide) was filled with tap and distilled water in various proportions in order to obtain of wide range of water resistivity (from 14 to $1000 \Omega . m$ ). Tap water resistivity was 14

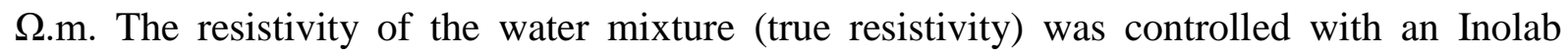
Comb Level 2 conductivity meter. The height of the solution in the container was constant (150 mm). A $300 \mathrm{~mm}$ long metal bar (diameter $8,16,32$ or $50 \mathrm{~mm}$ ) supported by two small strings was placed horizontally at the centre of the container at various distances (from 5 to $50 \mathrm{~mm}$ ) from the water surface in order to model different cover thicknesses (Figure 4). The DIAMOND probe was placed at the centre of the water surface, above the centre of the rebar and electrically connected to the bar. Constant current was injected $\left(J_{P}=10 \mu \mathrm{A}\right)$ and the instantaneous ohmic drop was measured for each rebar diameter/rebar distance from the surface configuration.

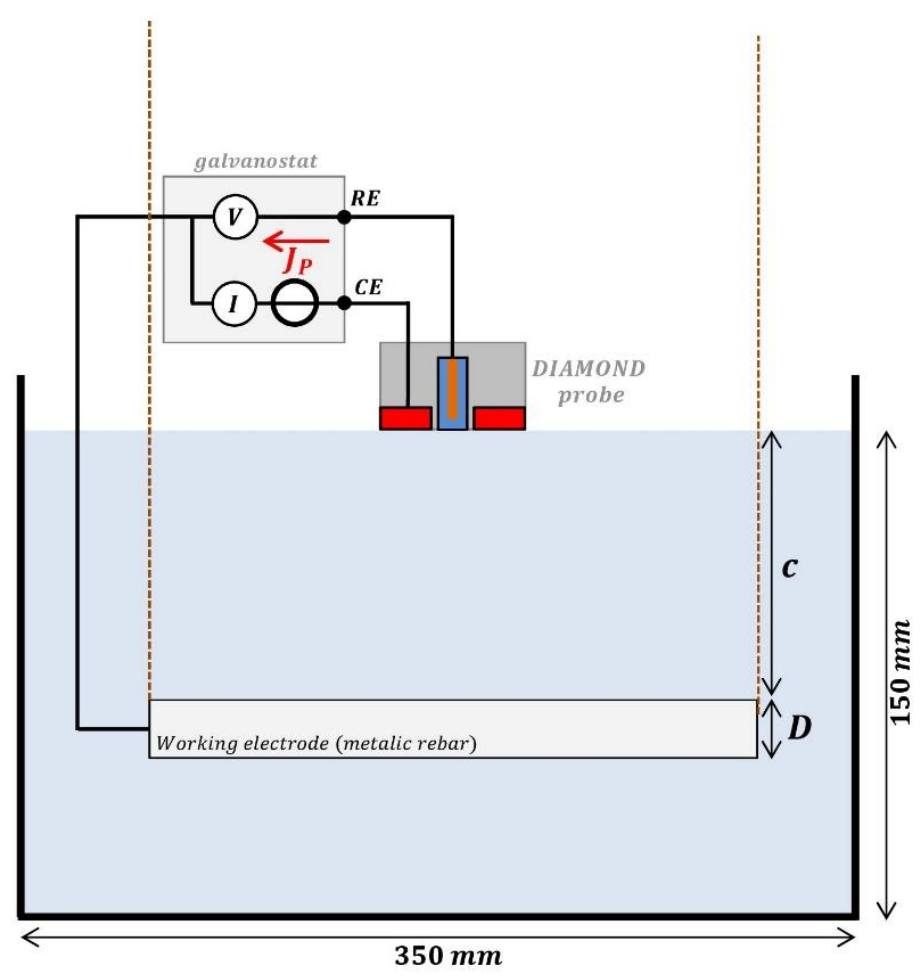

Figure 4. Experimental device schematic layout. 


\section{$5 \quad$ Numerical model}

\subsection{Constitutive law}

The numerical model was set up with a finite element method on COMSOL software with an AC/DC module. Concrete (or water for experimental validation) was assumed to be homogeneous and isotropic (uniform resistivity $\rho$ ). In the concrete volume, the electric field is governed by the local Ohm's law, which links the electrical current density vector $j\left[\mathrm{~A} / \mathrm{m}^{2}\right]$ to the electrical field vector $E[\mathrm{~V} / \mathrm{m}]$ :

$j=\frac{1}{\rho} E$

Eq. 6

In the system, the amount of charge was conserved, which meant that the amount of current flux entering an enclosed surface of a material was equal to the amount of current leaving it:

$\nabla \cdot j=0$

Eq. 7

\subsection{Geometry and mesh}

Preliminary numerical work was performed to determine a minimum representative volume for the instantaneous response and steady-state response. It aimed to find the minimum domain size that would not induce size effects in any of the modelled configurations, in order to optimize computation efficiency. The volume found to be most appropriate was $500 \times 500$ x $300 \mathrm{~mm}^{3}$. The steady-state response depended significantly on the slab geometry but the instantaneous response was hardly influenced by the slab dimensions. Only a quarter of the system was modelled because of the double symmetry of the problem. The DIAMOND probe was placed just over the rebar. The current was injected through the CE. Different CE diameters were modelled $(20,22,30,40,50,60$ and $70 \mathrm{~mm})$. The RE was a cylinder in contact with the surface and the CE was a disc with a hole in it to enable RE contact with surface (Figure 5). The injected current $J_{P}$ was kept at $10 \mu \mathrm{A}$ for all numerical experiments. 
RE and CE resistivity was $10^{-5} \Omega . m$. Different rebar diameters were modelled $(4,8,16,32$ and $50 \mathrm{~mm}$ ). Concrete cover ranged between 1 and $160 \mathrm{~mm}$.

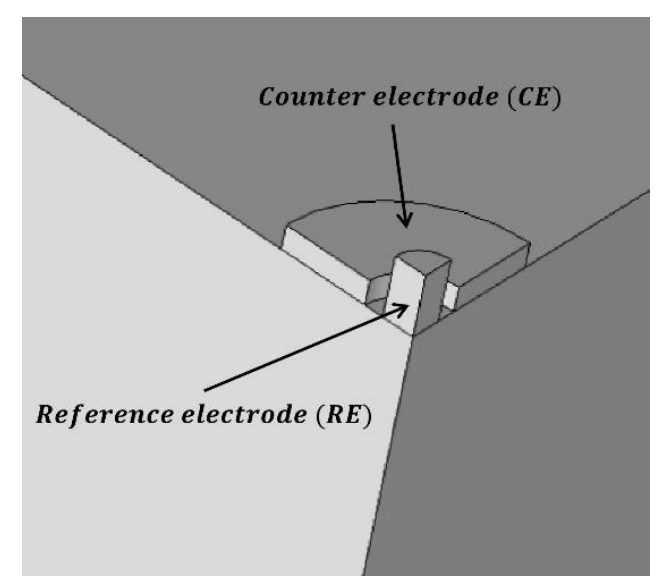

\section{Figure 5. Modelled DIAMOND probe.}

For a single bar, two different zones were defined on the rebar. The first one (zone 1 in Figure 6 (a)) was a $40 \mathrm{~mm}$ long zone directly under the probe. The second one (zone 2 in Figure 6 (a)) corresponded to the remaining part of the rebar.
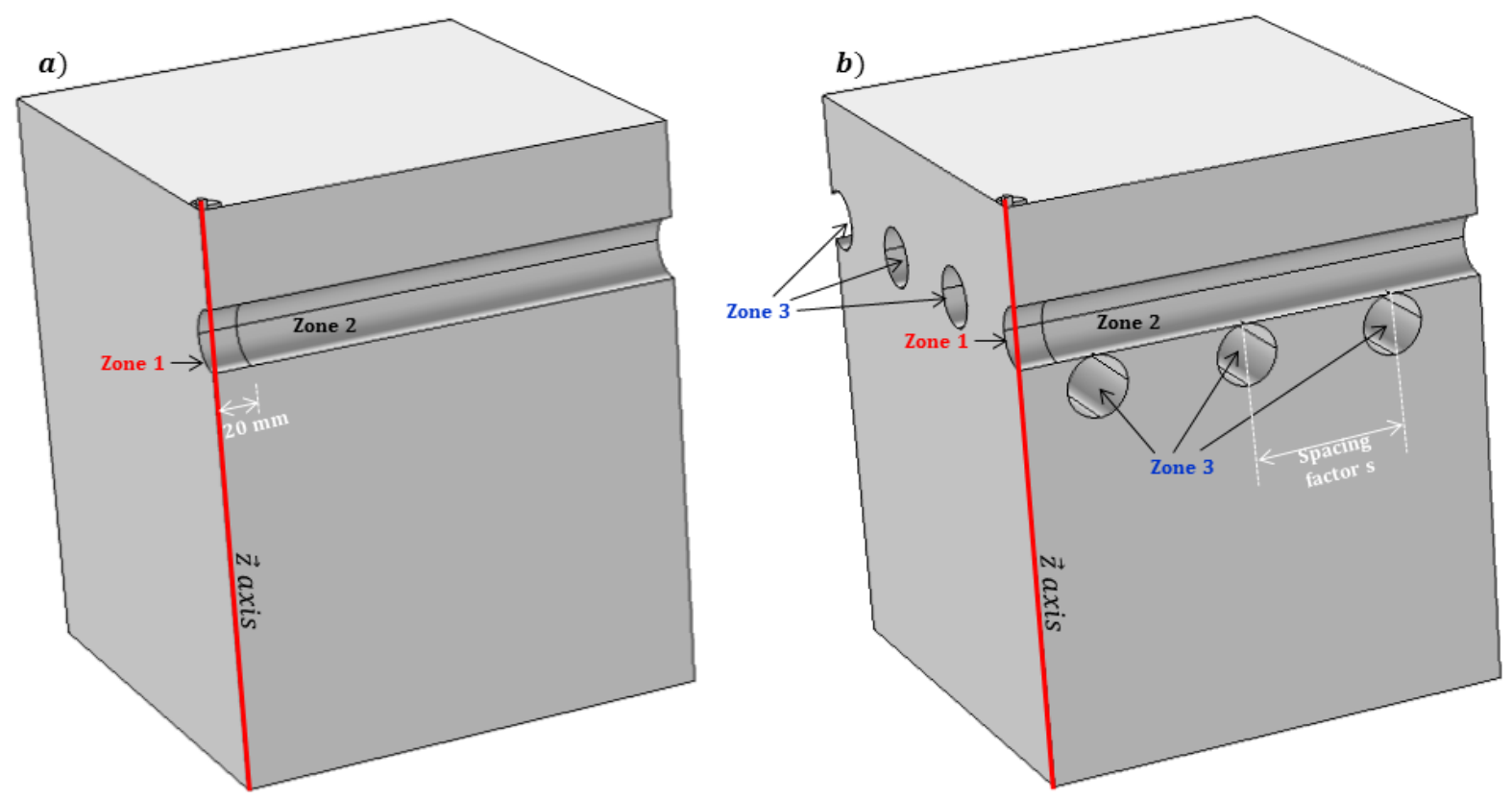

Figure 6. Modelled geometry. $D=32 \mathrm{~mm}$ and $c=50 \mathrm{~mm}$. Single bar (a), multiple bar with spacing $s=80 \mathrm{~mm}(\mathrm{~b})$. 
On-site, reinforcements are made with a metal framework composed of single perpendicular bars that were regularly spaced and generally electrically connected. To better represent what can be encountered on-site and to investigate the influence of rebar spacing on the concrete resistivity measurement protocol developed, several perpendicular rebars were modelled (Figure 6 (b)). The rebar spacing $s$ was the distance between the central axis of two consecutive parallel bars and it ranged from $40 \mathrm{~mm}$ to $280 \mathrm{~mm}$. The probe is placed over the centre of a rebar, at equal distance of the two next perpendicular rebars of the framework (Figure 6 (b)). For this configuration, a third zone was introduced (zone 3 in Figure 6 (b)), corresponding to all the rebar(s)/concrete interface that did not belong to the primary bar (zones 1 and 2).

Tetrahedral elements were used for discretization. The maximum element size was fixed at $0.5 \mathrm{~mm}$. The mesh was refined around the probe, the rebar surface and the $\vec{z}$ axis. The $\vec{z}$ axis was the axis passing through the centre of the RE and the top part of the rebar. It is represented by a red line in Figure 6.

In the simulation, a constant current density was applied to the $\mathrm{CE}\left(J_{P} /\right.$ surface area of the $\mathrm{CE}$ ). The corrosion potential of the rebar was imposed $E_{\text {corr }}=-0.42 \mathrm{~V}$ and was intended to model an active rebar [23,31]. However, changing this potential did not change any of the numerical results given below. A very small electric resistance $(0.00001 \Omega)$ was implemented on the rebar/concrete interface to model the polarization resistance short-cut at the beginning of the polarization. All other boundaries were electrically isolated.

\section{Results and discussion}

\subsection{Influence of cover thickness and rebar diameter}

Most of the results in the discussion section are presented for a $22 \mathrm{~mm}$ CE diameter (DIAMOND probe). The electrical potential on the surface of the domain studied is 
introduced in Figure 7 for an example where $c=60 \mathrm{~mm}, D=32 \mathrm{~mm}$, and $\rho=1000 \Omega . \mathrm{m}$. The potential is maximum on the $\mathrm{CE}$ where the current is injected, while it remains equal the corrosion potential at the rebar due the small electrical resistance. Elsewhere in the modelled domain, the potential remains quite constant and small.

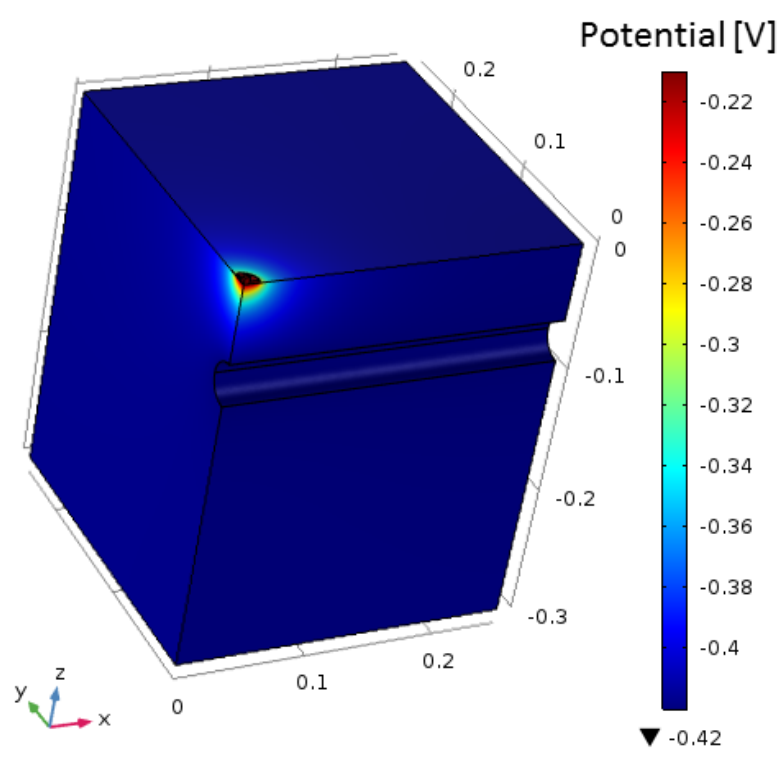

Figure 7. Electrical potential on the surface of the studied domain for a concrete cover $c$ of $60 \mathrm{~mm}$, a rebar having a diameter $D$ of $32 \mathrm{~mm}$, and a concrete resistivity $\rho$ of $1000 \Omega . m$.

To quantitatively visualize the ohmic drop between the surface and the rebar, the electrical potential evolution along the $\vec{z}$ axis is presented in Figure 8. The potential evolution is represented for two concrete covers $(10$ and $60 \mathrm{~mm}$ ) and two rebar diameters, $8 \mathrm{~mm}$ (straight lines) and $32 \mathrm{~mm}$ (dotted lines).

In Figure 8 (a), CE diameter is $22 \mathrm{~mm}$ (DIAMOND probe). Without injected current, the potential measured on the surface is equal to the corrosion potential $\left(E_{c o r r}=-0.42 \mathrm{~V}\right)$. Current injection leads to a potential ohmic drop between the rebar and the surface. At the beginning of the polarization, on the rebar interface, the potential remains equal to the corrosion potential (see Figure 2 (c)). Thus, the potential measured at the surface minus the corrosion 
potential represents the instantaneous ohmic drop $\Delta E_{\Omega}$ between the surface and the rebar. Figure 8 (a) shows that this ohmic drop depends on concrete cover. The ohmic drop increases with concrete cover. Moreover, the rebar diameter also impacts the ohmic drop, especially if the concrete cover is thin ( $c=10 \mathrm{~mm}$, for example, in Figure 8). If the rebar diameter is large, the area through which current can flow is larger and the measured ohmic drop decreases. In Figure 8 (b), the CE diameter is $60 \mathrm{~mm}$. A different potential evolution is observed along the $\vec{Z}$ axis. When the CE diameter is increased, the instantaneous ohmic drop decreased for the same reason explaining why the ohmic drop decreased when the rebar diameter is increased.
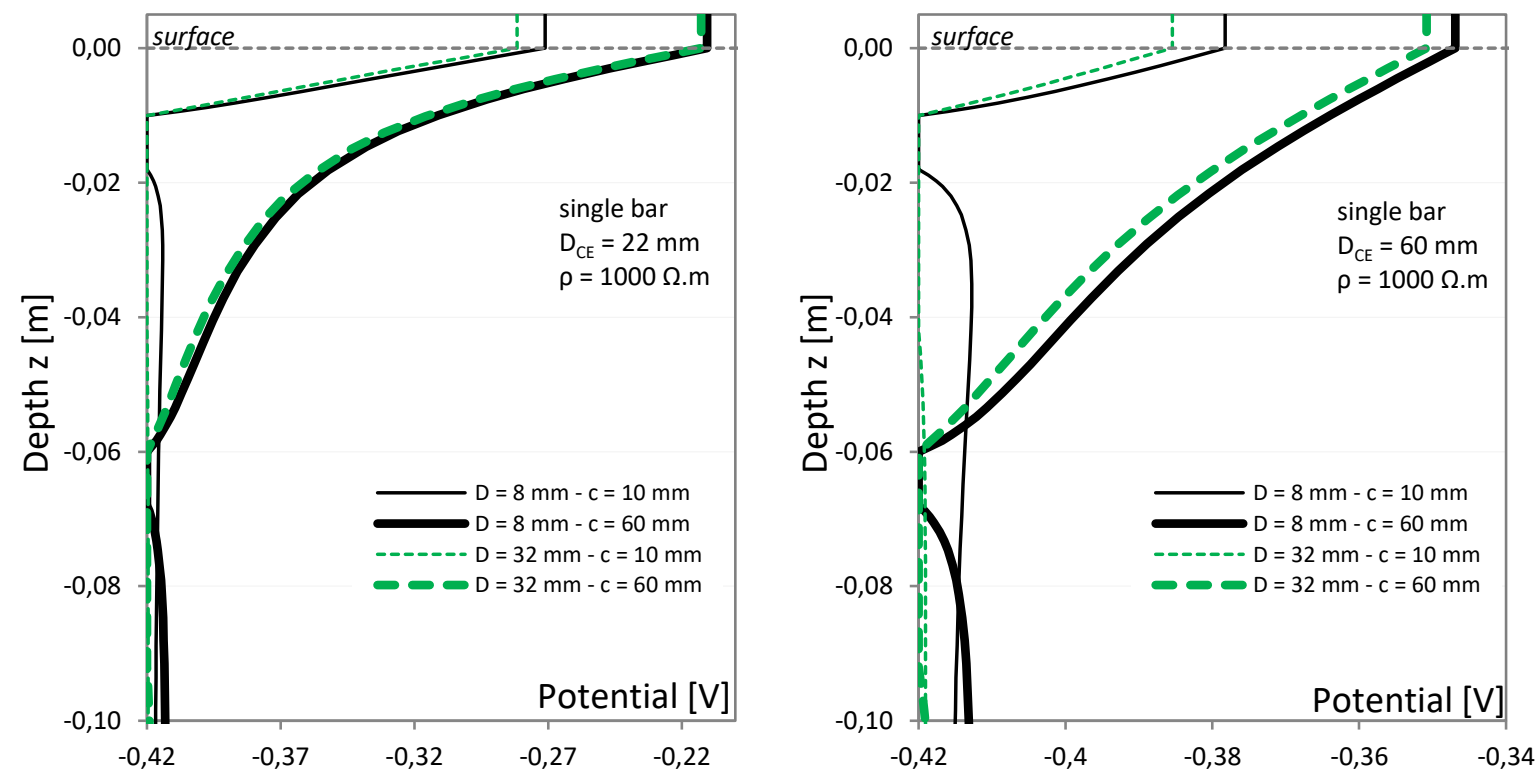

Figure 8. Electrical potential along $\vec{Z}$ axis for two concrete covers $(10$ and $60 \mathrm{~mm})$ and two rebar diameters $(8$ and $32 \mathrm{~mm}) ; \rho=1000 \Omega . \mathrm{m} ; D_{C E}=22 \mathrm{~mm}(\mathrm{a}), D_{C E}=60 \mathrm{~mm}(\mathrm{~b})$.

To visualize concrete cover resistivity influence on potential evolution along the $\vec{z}$ axis, Figure 9 is introduced. Compared to Figure 8, the concrete cover resistivity was divided by ten (i.e. $100 \Omega . m$ ). 


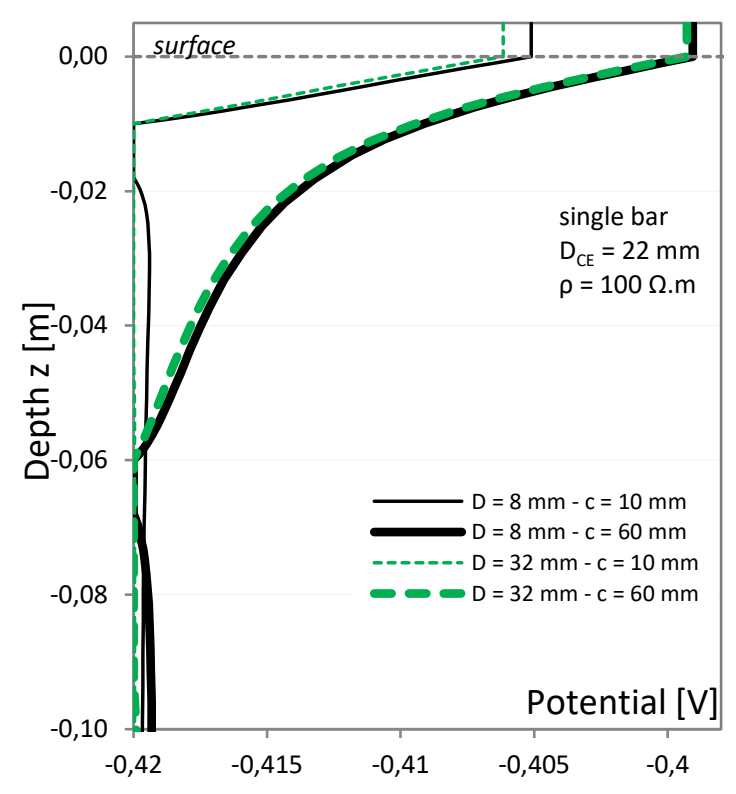

Figure 9. Electrical potential along $\vec{z}$ axis for two concrete covers (10 and $60 \mathrm{~mm}$ ) and two rebar diameters (8 and $32 \mathrm{~mm}) ; \rho=100 \Omega . \mathrm{m} ; D_{C E}=22 \mathrm{~mm}$.

Reducing concrete cover resistivity significantly reduced the ohmic drop. Similar potential evolutions were observed if the resistivity was changed.

\subsection{Geometrical factor $k$ abacus construction}

Concrete resistance $R_{\Omega}$ does not depend on the injected current. However, concrete resistance depends on concrete resistivity as shown in Figure 10 for a $10 \mathrm{~mm}$ concrete cover. A proportional relationship appears between resistance and resistivity. It can be seen that this relation depends on CE diameter but also on rebar diameter. This relation is also modified with the concrete cover: concrete resistance increases with concrete cover. 


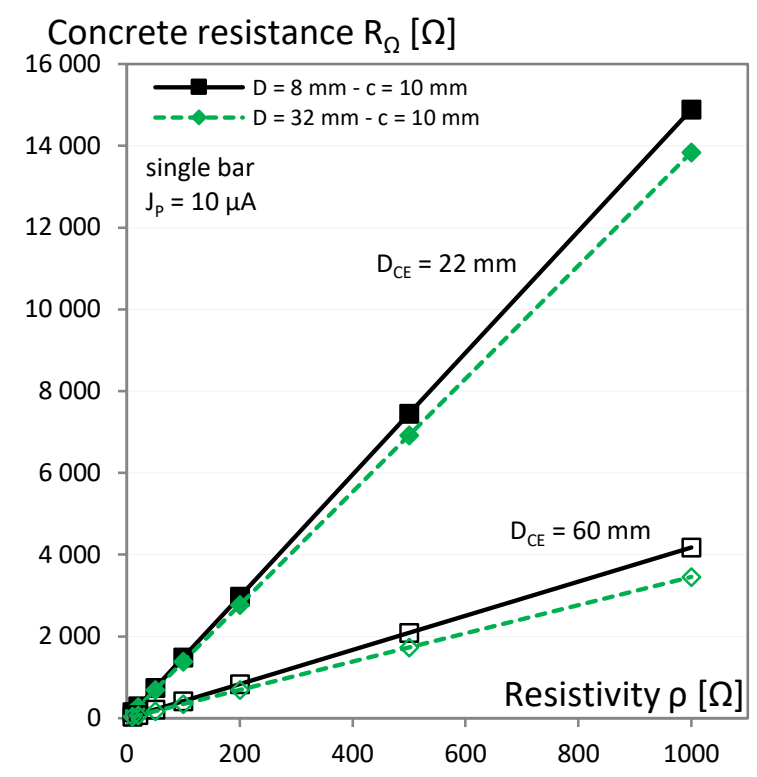

Figure 10. Concrete resistance $R_{\Omega}[\Omega]$ versus resistivity for two rebar diameters, $8 \mathrm{~mm}$ (dotted lines) and $32 \mathrm{~mm}$ (continuous lines) and two CE diameters, $22 \mathrm{~mm}$ (full markers) and $60 \mathrm{~mm}$ (empty markers).

The slope $k$, (ratio between concrete resistance and concrete resistivity) was calculated for several configurations that can be encountered on-site and is presented in Figure 11 for two CE diameters (22 mm (a), $60 \mathrm{~mm}$ (b)) for concrete cover ranging from 10 to $160 \mathrm{~mm}$. On-site, most concrete covers exceed $10 \mathrm{~mm}$. However, reinforced concrete structure can suffer from construction defects which lead to very thin concrete cover and associated corrosion problems. It explains why we decided to determine the slope $k$ for concrete cover ranging from 1 to $160 \mathrm{~mm}$ so that the reader can use the presented abacus (appendix) for any cover find on-site. The slope $k$ is then referred to as the geometrical factor. For the sake of clarity, only five rebar diameters are presented.

For $22 \mathrm{~mm} \mathrm{CE}$ diameter (Figure 11 (a)), if the concrete cover is thicker than $10 \mathrm{~mm}$, the geometrical factor $k$ no longer depends almost solely on rebar diameter. The relation between concrete resistance and concrete resistivity mostly depends on the concrete cover. When the concrete cover is very small $(<10 \mathrm{~mm}$, appendix $), k$ increases significantly with rebar 
diameter. Moreover, we added the analytical result by Feliu [17] that obtain a geometrical factor equal to $2 D_{C E}(44 \mathrm{~mm}$ for our device). Feliu specified that this formula can only be applied when the concrete cover is greater than about twice diameter of the CE. This area corresponds to the grey section in Figure 11. This validity area is also represented in the appendix by values in italics for each CE diameter. The results obtained by our model and obtained by Feliu perfectly match for the higher concrete cover simulated $(160 \mathrm{~mm})$. However, differences appeared even when the cover is equal to twice CE diameter. The 3D numerical simulation we developed can now be employed to obtain the geometrical factor when the concrete cover is smaller than this limit $(c<44 \mathrm{~mm})$. Our CE is quite small $\left(D_{C E}=22 \mathrm{~mm}\right)$ which means that the Feliu's model can only be applied when the concrete cover is bigger than $44 \mathrm{~mm}$ which is a value that can be found on-site. However, bigger CE can be found on literature (i.e. $70 \mathrm{~mm}$ for GECOR and $60 \mathrm{~mm}$ for Galvapulse [12]) which mean that the Feliu model could only be applied for very thick concrete covers that are rarely found on-site. The Feliu validity area decreases when the CE diameter is increased as shown on both Figure 11 and appendix by values in italics. For example, with a $60 \mathrm{~mm}$ diameter CE (Figure $11(\mathrm{~b})$ ), the $k$ slope value given by Feliu model is $0.12 \mathrm{~mm}$ (for all concrete covers and rebar diameters). The numerical simulation shows that for a concrete cover of $30 \mathrm{~mm}$, for a $16 \mathrm{~mm}$ rebar diameter the $k$ slope is 0.169 (Figure 11 (b) or appendix) which corresponds to an error of around $30 \%$. With a $10 \mathrm{~mm}$ concrete cover the error reach $55 \%(k=0.263)$. Feliu model leads to concrete resistivity underestimation when the concrete cover is less than two CE diameters, as announced by the authors. 

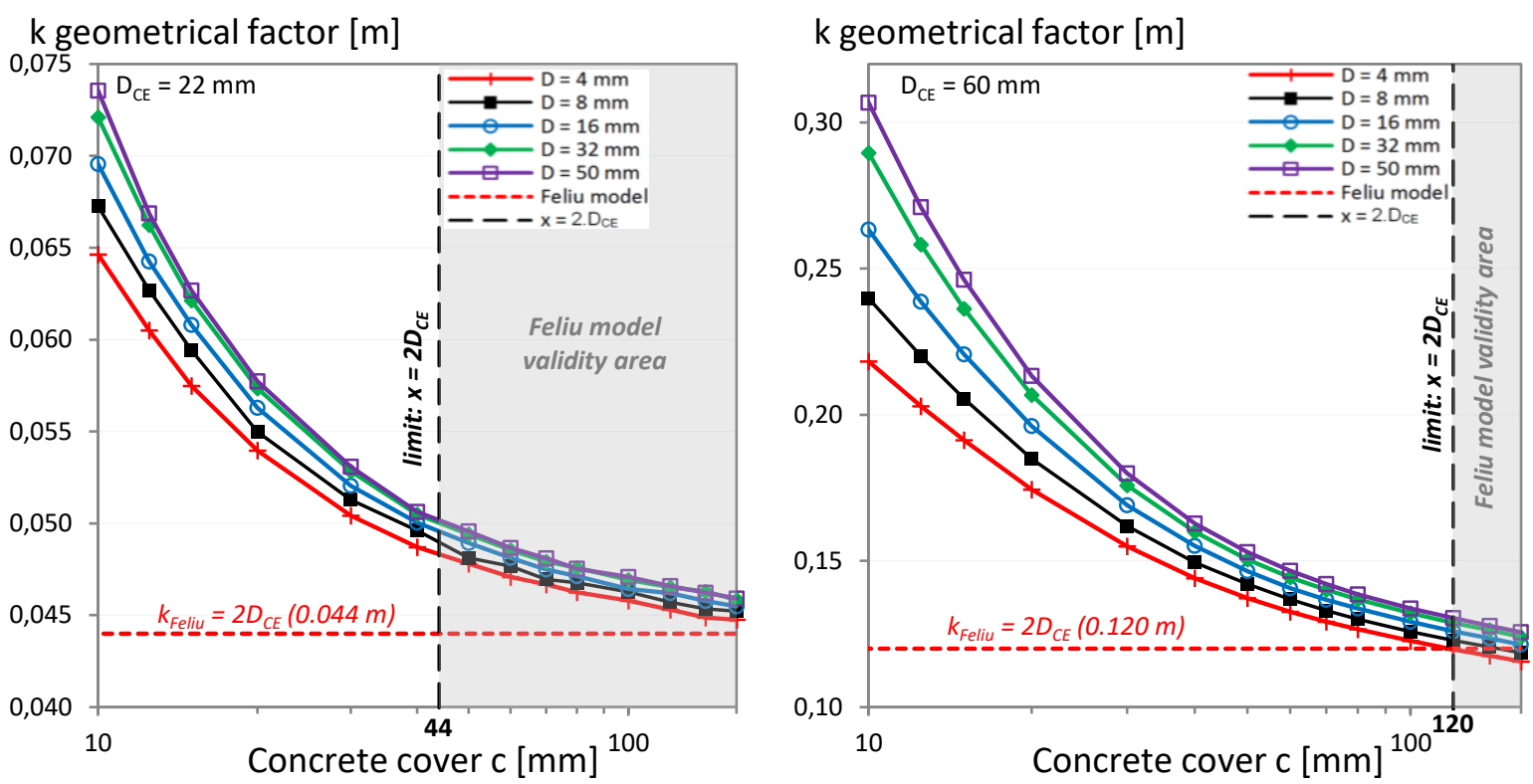

Figure 11. Geometrical factor $k$ of a single rebar depending on concrete cover for five rebar diameters and Feliu's geometrical factor. Values can be find in appendix.

\subsection{Resistivity measurement procedure}

The experimental procedure for determining concrete resistivity on-site is:

- $\quad$ CE diameter $D_{C E}$, concrete cover $c$ and rebar diameter $D$ measurements

- $\quad k$ geometrical factor determination (Figure 11 or appendix)

- DIAMOND probe positioning above the centre of the rebar

- Instantaneous ohmic drop $\Delta E_{\Omega}$ measurement

- Concrete resistance $R_{\Omega}$ calculation

- Concrete cover resistivity calculation $\left(\rho=k \cdot R_{\Omega}\right)$

This method can be employed for micro or macro-cell corrosion systems since the polarization resistance is short-cut.

\subsection{Experimental validation}

This resistivity calculation procedure was employed on the water tank filled with water of known resistivity (true resistivity). Water resistance $R_{\Omega}$ was experimentally evaluated for 84 
configurations ( 7 water covers, 6 water resistivities and 4 rebar diameters) with the $22 \mathrm{~mm}$ probe. Water resistance increases with water resistivity and cover.

The measured resistances were then multiplied by the numerically determined geometrical factor $k$ (Figure 11 (a)) to calculate the water resistivities (Figure 12):
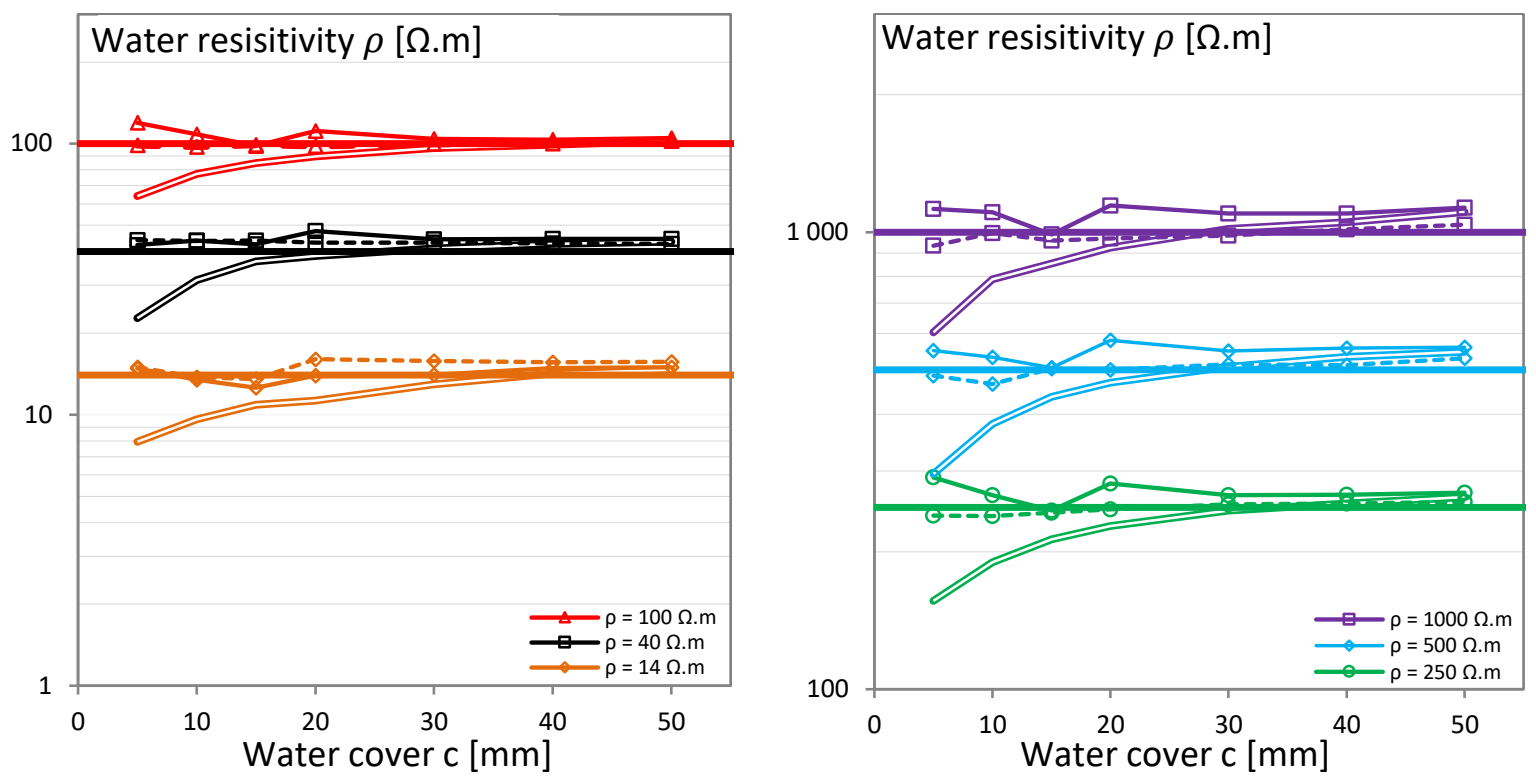

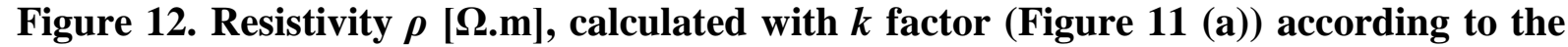
concrete cover for two rebar diameters, $8 \mathrm{~mm}$ (dotted lines) and $32 \mathrm{~mm}$ (continuous lines). Straight lines are true resistivities. Hollow lines are Feliu resistivity $(D=8 \mathrm{~mm})$. $\rho$ $=14,40$ and $100 \Omega . m(a), \rho=250,500$ and $1000 \Omega . m(b)$.

A good correlation was obtained between the calculated and the true resistivities (straight horizontal lines in Figure 12) for all rebar diameter/water cover configurations tested, which validated the numerical approach developed in this article. However, calculated resistivities remained slightly higher than the true resistivities. Calculated values were $5 \%$ higher than real ones on average. An internal resistance in our experimental system that was not taken into account in our numerical model may explain the small differences observed. The resistivity calculated with the Feliu's analytical formulae is also represented for $D=8 \mathrm{~mm}$ 
(with hollow lines - Figure 12). As expected, the calculated resistivity are in good correlation with the true resistivity when the concrete cover exceed twice the diameter (i.e. $44 \mathrm{~mm}$ ).

\subsection{Influence of rebar spacing}

The influence of the rebar spacing factor $s$ on the concrete resistivity estimation was investigated numerically. With a mesh of rebars (Figure 6 (b)), the relation between concrete resistance and concrete resistivity might be different from what was modelled for a single bar as the proximity of the other rebars could modify the ohmic drop. The spacing factor $s$, (distance between the central axes of two consecutive parallel bars) may influence the $k$ geometrical factor created (Figure 11 and appendix). A single rebar corresponds to an infinite $s$. Four rebar spacings $(40,80,120$ and $240 \mathrm{~mm})$ were investigated. The next results are obtained for a $22 \mathrm{~mm} \mathrm{CE}$ diameter.

The investigation began by following current lines through the modelled concrete block on a single rebar diameter/concrete cover configuration $(c=50 \mathrm{~mm}, D=32 \mathrm{~mm})$ for three different rebar spacings ( $\infty$ (single bar), 240 and $80 \mathrm{~mm}$ ). The total current received by the three zones defined in Figure 6 (b) is detailed In Table 1. For a single bar, around a quarter of the injected current flowed through zone $1(25.5 \%)$, the other part flowing through zone 2 . Reducing the spacing factor resulted in other bars being taken into account, which enabled the current to disperse and to flow through these new rebar/concrete interfaces (zone 3). Thus, the percentages of current flowing through zones 1 and 2 decreased when the spacing factor decreased. 
Table 1. Current distribution in the three zones for $50 \mathrm{~mm}$ concrete cover and three spacing factors $(\infty, 240$ and $80 \mathrm{~mm})$ for a total of 2000 current lines. $D=32 \mathrm{~mm} . D_{C E}=$ $22 \mathrm{~mm}$.

\begin{tabular}{ccccc} 
& & \multicolumn{3}{c}{ Current \% } \\
\cline { 2 - 5 } & zone $^{\circ}$ & 1 & 2 & 3 \\
\hline \multirow{3}{*}{$\mathrm{s}[\mathrm{mm}]$} & $\infty$ & 25.5 & 74.5 & 0.0 \\
& 240 & 23.4 & 48.5 & 28.1 \\
& 80 & 19.9 & 34.6 & 45.6
\end{tabular}

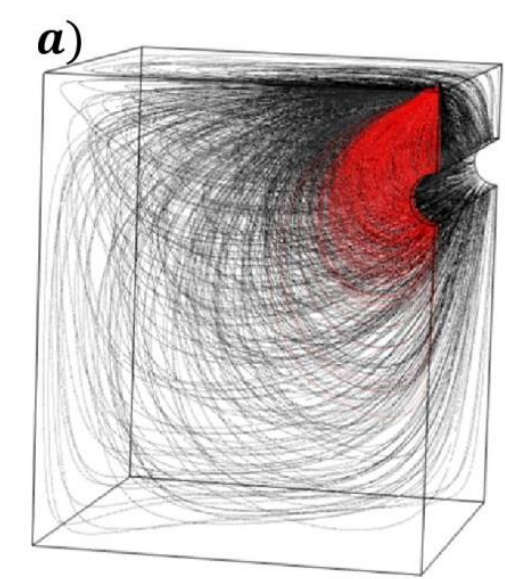

\section{b)}

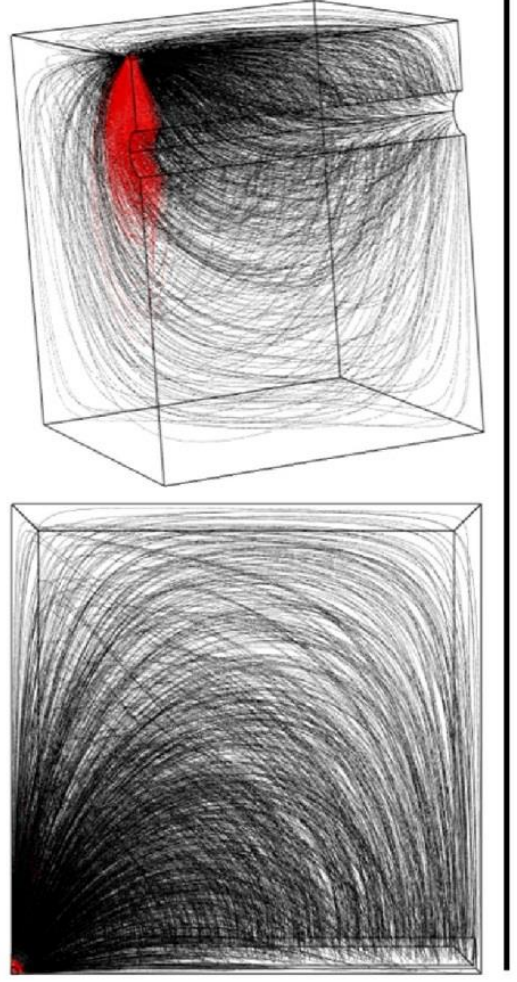

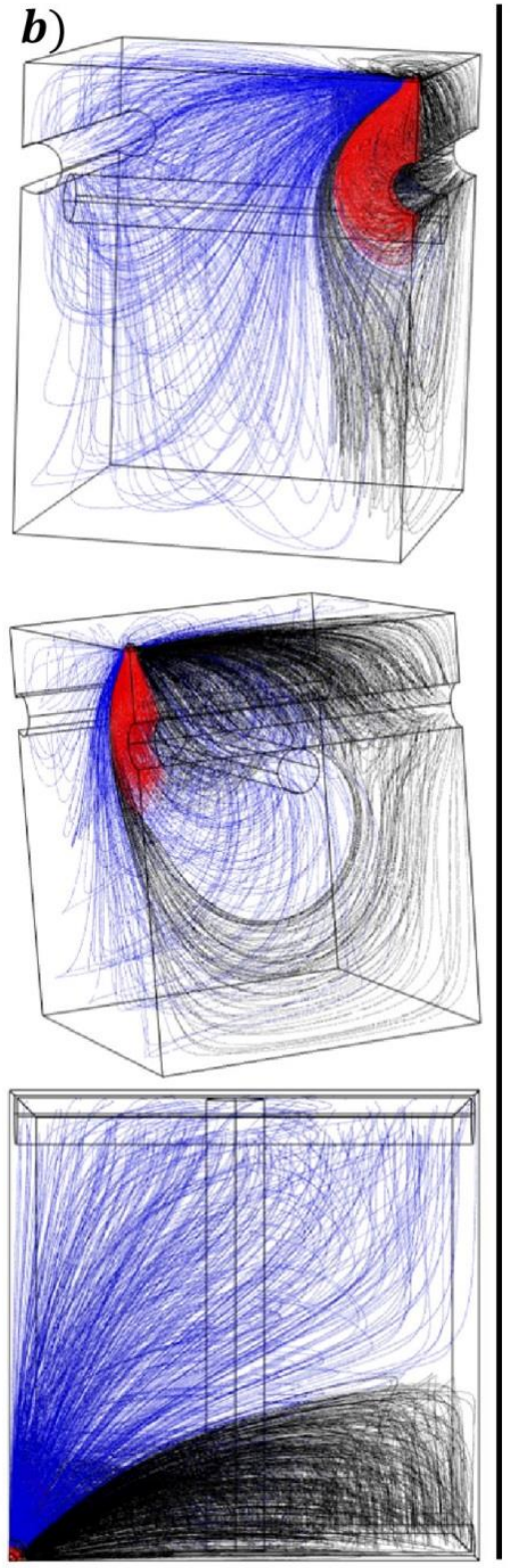

c)
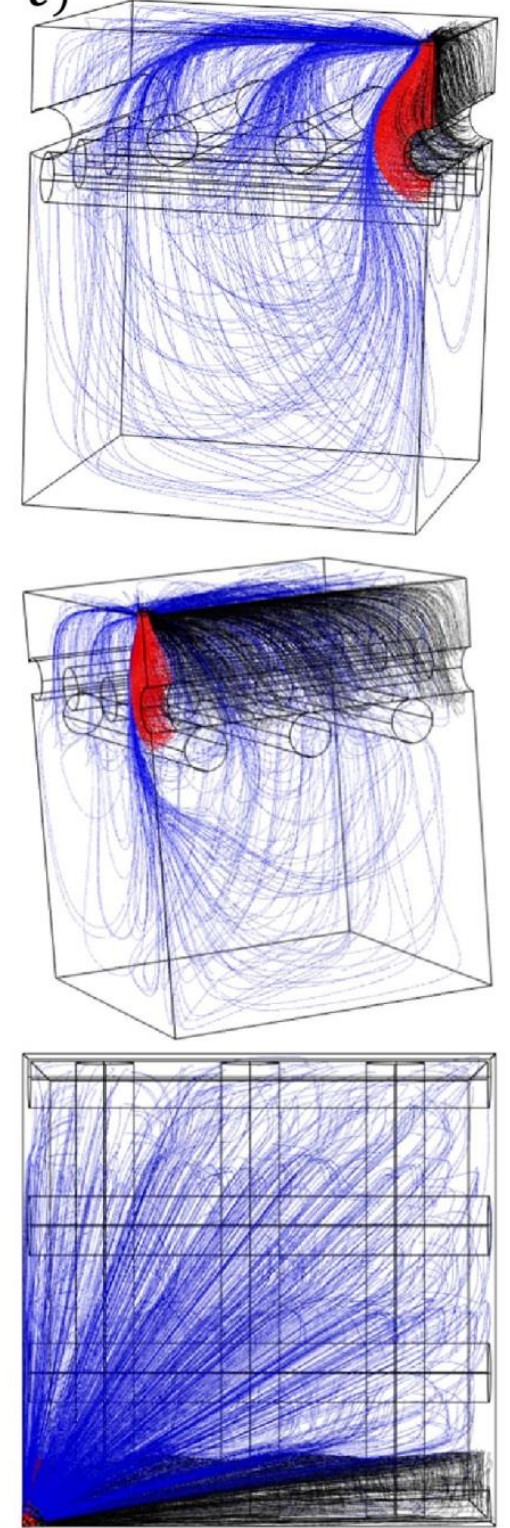
Figure 13. Current line distribution for concrete cover of $50 \mathrm{~mm}$ and rebar diameter of $32 \mathrm{~mm} . s=\infty\left(\right.$ a) $, s=240 \mathrm{~mm}(\mathrm{~b}), s=80 \mathrm{~mm}(\mathrm{c}) . D_{C E}=22 \mathrm{~mm}$. Red (zone $1-4 \mathrm{~cm}$ area), black (zone 2 - the rest of the primary bar), blue (zone 3 - other bar(s)).

Figure 13 gives a visual representation of the current distribution. For each configuration, 2000 current lines are represented. Three colours have been introduced to distinguished current lines flowing through the three zones (zone $1=$ red, zone $2=$ black, zone $3=$ blue). Current line distribution for a single bar $(s=\infty)$ is presented in Figure 13 (a). Current lines are distributed through the concrete block.

When the spacing factor is reduced $(s=240 \mathrm{~mm}$ - Figure $13(\mathrm{~b}))$, part of the current goes from the CE to the new bars (blue streamlines). In this particular example, it corresponds to $28.1 \%$ of the injected current. However, the proportion of current received by zone 1 changes only slightly (from 25.5 to $23.4 \%$ ). Adding other bars ( $s=80 \mathrm{~mm}$ - Figure 13 (c)) reduces the current received by the initial bar, especially by zone 2 .

Figure 14 quantifies how the current distribution evolves with concrete cover and rebar spacing. In Figure 14 (a), only a single rebar is considered. With very thin concrete cover, the majority of the current goes through zone 1, especially if the rebar diameter is large. In this configuration (22 $\mathrm{mm}$ diameter probe), the current percentage flowing through zone 1 is always higher if the rebar diameter is large. Increasing the concrete cover tends to distribute the current along the bar and the current percentage going through zone 2 increases (dotted lines in Figure 14 (a)).

Adding other bars (Figure 14 (b) and (c)) modifies the current distribution. However, the proportion of current flowing through zone 1 (continuous lines in Figure 14) is hardly modified by the spacing factor. Adding bars mostly modifies the current received by zone 2 . 


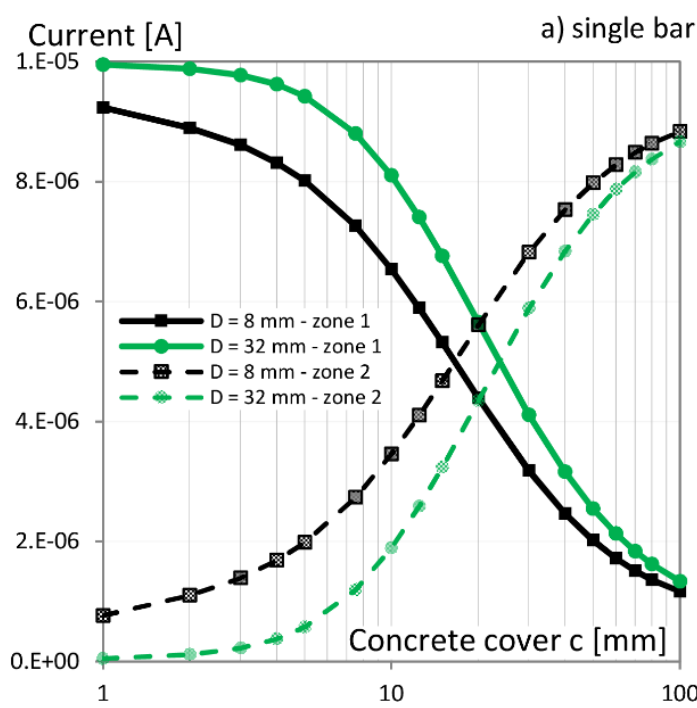

$\begin{array}{ll}\text { Current }[A] & \text { b) } \mathrm{s}=240 \mathrm{~mm}\end{array}$

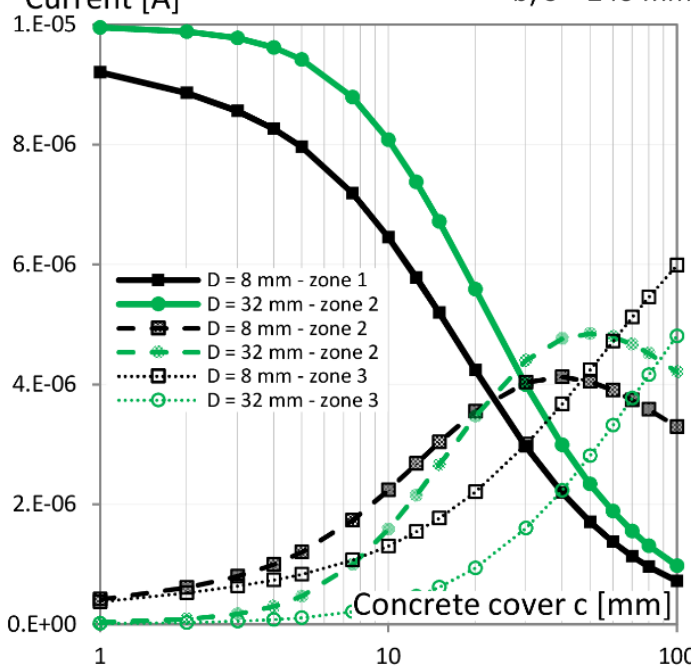

$\begin{array}{ll}\text { Current }[A] & \text { c) } \mathrm{s}=80 \mathrm{~mm}\end{array}$

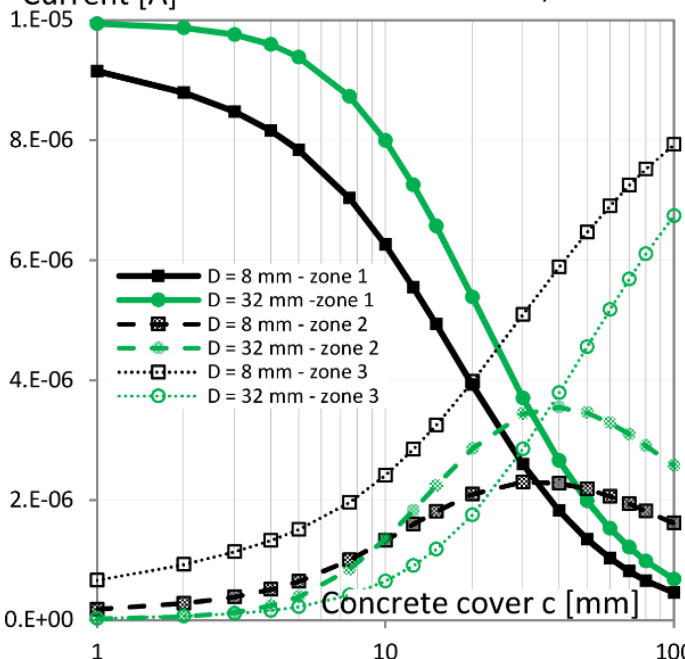


Figure 14. Current distribution in the three zones of the rebars according to concrete cover for two rebar diameters, $8 \mathrm{~mm}$ (green lines) and $32 \mathrm{~mm}$ (black lines). $D_{C E}$ $=22 \mathrm{~mm} . s=\infty(\mathrm{a}), s=240 \mathrm{~mm}(\mathrm{~b}), s=80 \mathrm{~mm}(\mathrm{c})$.

Figure 15 precisely quantifies the current distribution for the different spacing factors modelled considering a constant rebar diameter $(8 \mathrm{~mm})$. The current flowing through zone 1 is presented in Figure 15 (a). As could be sensed in Figure 14, the proportion of current flowing through zone 1 does not evolve greatly with rebar spacing and is maximum for a single rebar.

In contrast, the proportion of current flowing through zone 2 depends heavily on the rebar spacing (Figure 15 (b)) but, whatever the rebar spacing considered, the current received in zone 2 remains small if the concrete cover is small as the majority of the current goes through zone 1 . The proportion of current flowing through zone 2 decreases if rebar spacing decreases because a significant part of the current flows through zone 3. Similar conclusions can be drawn for other rebar diameters. 

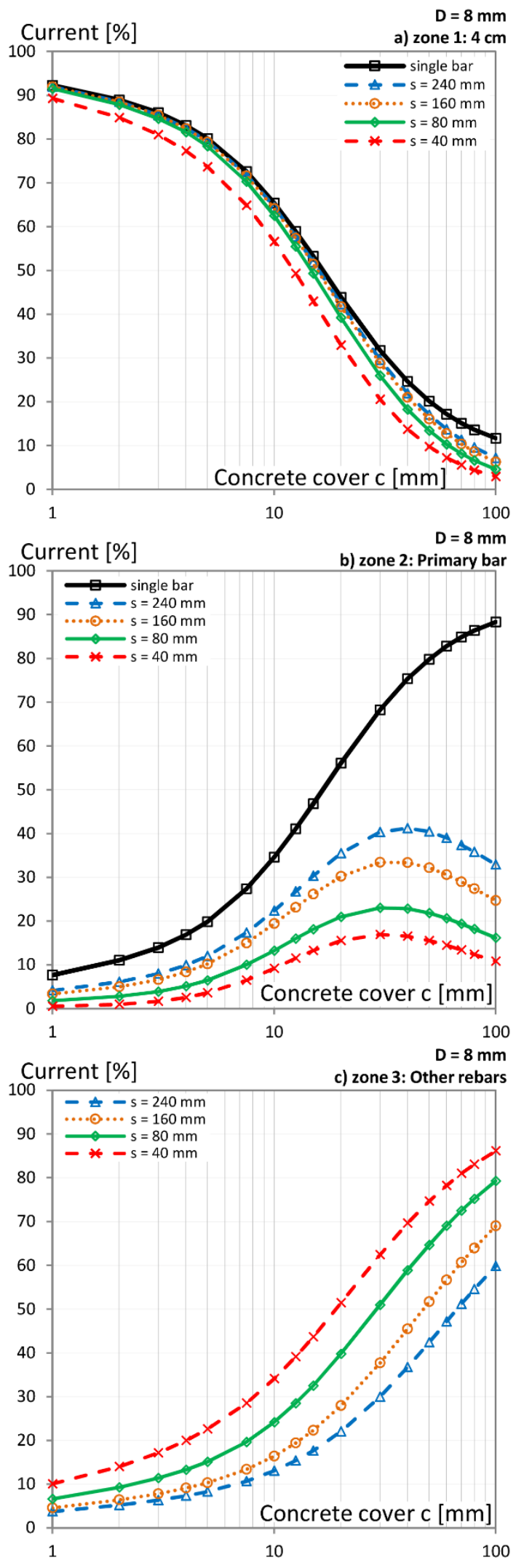

Figure 15. Current distributions according to concrete cover and rebar spacing. Rebar diameter = $32 \mathrm{~mm} . D_{C E}=22 \mathrm{~mm}$. Zone 1 (a), zone 2 (b), zone 3 (c). 
The evolution of the ohmic drop for two rebar diameters (8 and $32 \mathrm{~mm}$ ) and three rebar spacings $(\infty, 240$ and $80 \mathrm{~mm})$ is presented in Figure 16. This figure makes it clear that the ohmic drop does not depend on rebar spacing and depends only on concrete cover and rebar diameter. The differences observed when the spacing factor is modified are always lower than $2 \%$.This means that the geometrical factor $k$, presented on Figure 11 can be used for any rebar spacing factor. The only parameters required to determine the concrete resistivity are the concrete cover, the rebar diameter and the measured ohmic drop. Similar conclusions were made for all the tested CE diameters.

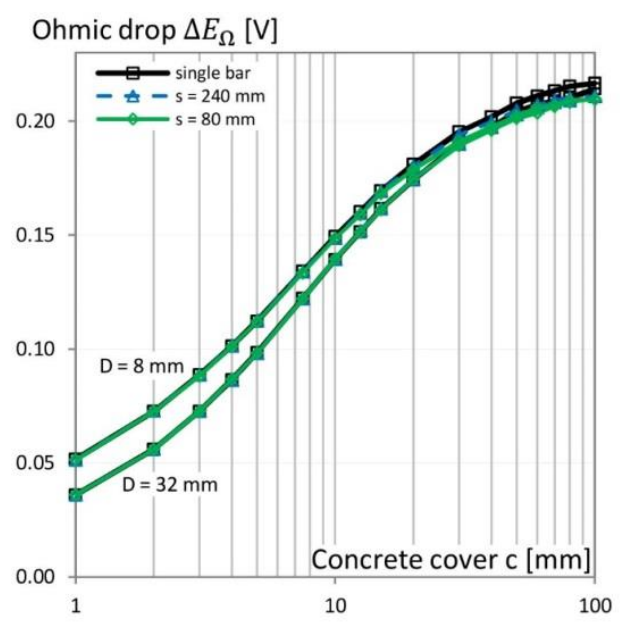

Figure 16. Ohmic drop $\Delta E_{\Omega}$ in concrete according to concrete cover for two rebar diameters (8 and $32 \mathrm{~mm})$ and three rebar spacings $(\infty, 240$ and $80 \mathrm{~mm}) ; \rho=1000 \Omega . \mathrm{m}$.

\section{Conclusions}

A new device to assess concrete resistivity has been proposed. Its geometry is simple (no guard ring): the current is injected through an annular $\mathrm{CE}$ and the potential is measured on the surface. The resistivity measurement developed is based on the instantaneous ohmic drop measured at the beginning of the polarization. A numerical model was set up in COMSOL Multiphysics® in order to link the measured ohmic drop to the concrete resistivity, knowing rebar diameter and concrete cover. The built abacuses can be used to determine concrete resistivity for a wide range of concrete cover, from 1 to $160 \mathrm{~mm}$ (unlike the previous model 
by Feliu). The model is generalized for a wide range a CE diameter (from 20 to $70 \mathrm{~mm}$ ) and presented on a summary table in appendix. The theory developed was confirmed by experiments performed on water of known resistivity. This methodology (measurement and 3D reverse calculation) can be used by the researchers or engineers that use galvanostatic measurements to measure the corrosion rate of the metal rebar to also determine the concrete cover resistivity. This method can be used for both micro- and macro-cell corrosion systems. Finally, the influence of the rebar framework on the developed procedure was investigated numerically. The investigations proved that the graphs established are independent of the rebar spacing (unlike in the Wenner method). The methodology was built with homogeneous material and with a perfect electrical contact between the probe and the concrete. Furthers works are required to investigate the ability of the probe to measure the concrete cover on real concrete structure. 
8 Appendix: geometrical factor $\mathbf{k}$ depending on rebar diameter and concrete cover for different CE diameter. Values in italics represent the Feliu validity model area (concrete cover $\geq 2 D_{C E}$ ) as depicted in grey in Figure 11.

\begin{tabular}{|c|c|c|c|c|c|c|c|c|c|c|c|c|c|c|c|c|c|c|c|c|c|}
\hline $\begin{array}{c}\text { CE } \\
\text { diameter } \\
{[\mathrm{mm}]}\end{array}$ & $\begin{array}{l}\text { Conckete cover c [mm] } \\
\text { Rebar diameter D }[\mathrm{mm}]\end{array}$ & 1 & 2 & 3 & 4 & 5 & 7.5 & 10 & 12.5 & 15 & 20 & 30 & 40 & 50 & 60 & 70 & 80 & 100 & 120 & 140 & 160 \\
\hline \multirow{11}{*}{20} & 4 & 0.145 & 0.108 & 0.090 & 0.080 & 0.073 & 0.063 & 0.057 & 0.054 & 0.051 & 0.048 & 0.045 & 0.044 & 0.043 & 0.042 & 0.042 & 0.042 & 0.041 & 0.041 & 0.041 & 0.040 \\
\hline & 6 & 0.161 & 0.116 & 0.096 & 0.084 & 0.076 & 0.064 & 0.058 & 0.054 & 0.052 & 0.049 & 0.046 & 0.044 & 0.043 & 0.043 & 0.042 & 0.042 & 0.042 & 0.041 & 0.041 & 0.041 \\
\hline & 8 & 0.174 & 0.122 & 0.100 & 0.087 & 0.078 & 0.066 & 0.059 & 0.055 & 0.052 & 0.049 & 0.046 & 0.045 & 0.044 & 0.043 & 0.042 & 0.042 & 0.042 & 0.041 & 0.041 & 0.041 \\
\hline & 10 & 0.184 & 0.127 & 0.103 & 0.089 & 0.080 & 0.067 & 0.060 & 0.056 & 0.053 & 0.049 & 0.046 & 0.044 & 0.044 & 0.043 & 0.043 & 0.042 & 0.042 & 0.041 & 0.041 & 0.041 \\
\hline & 12 & 0.193 & 0.132 & 0.106 & 0.091 & 0.082 & 0.068 & 0.060 & 0.056 & 0.053 & 0.050 & 0.046 & 0.045 & 0.044 & 0.043 & 0.043 & 0.042 & 0.042 & 0.042 & 0.041 & 0.041 \\
\hline & 14 & 0.201 & 0.136 & 0.109 & 0.093 & 0.083 & 0.069 & 0.061 & 0.056 & 0.053 & 0.050 & 0.046 & 0.045 & 0.044 & 0.043 & 0.043 & 0.042 & 0.042 & 0.042 & 0.041 & 0.041 \\
\hline & 16 & 0.207 & 0.140 & 0.111 & 0.094 & 0.084 & 0.069 & 0.061 & 0.056 & 0.053 & 0.050 & 0.046 & 0.045 & 0.044 & 0.043 & 0.043 & 0.043 & 0.042 & 0.042 & 0.041 & 0.041 \\
\hline & 20 & 0.219 & 0.145 & 0.114 & 0.097 & 0.085 & 0.070 & 0.062 & 0.057 & 0.054 & 0.050 & 0.047 & 0.045 & 0.044 & 0.043 & 0.043 & 0.043 & 0.042 & 0.042 & 0.041 & 0.041 \\
\hline & 25 & 0.231 & 0.151 & 0.118 & 0.099 & 0.087 & 0.070 & 0.062 & 0.058 & 0.054 & 0.050 & 0.047 & 0.045 & 0.044 & 0.044 & 0.043 & 0.043 & 0.042 & 0.042 & 0.042 & 0.041 \\
\hline & 32 & 0.245 & 0.157 & 0.121 & 0.101 & 0.089 & 0.072 & 0.063 & 0.058 & 0.055 & 0.051 & 0.047 & 0.045 & 0.044 & 0.044 & 0.043 & 0.043 & 0.042 & 0.042 & 0.042 & 0.042 \\
\hline & 50 & 0.267 & 0.166 & 0.126 & 0.105 & 0.091 & 0.074 & 0.064 & 0.059 & 0.056 & 0.051 & 0.047 & 0.046 & 0.045 & 0.044 & 0.043 & 0.043 & 0.042 & 0.042 & 0.042 & 0.042 \\
\hline \multirow{11}{*}{22} & 4 & 0.162 & 0.121 & 0.102 & 0.091 & 0.083 & 0.071 & 0.065 & 0.061 & 0.057 & 0.054 & 0.050 & 0.049 & 0.048 & 0.047 & 0.047 & 0.046 & 0.046 & 0.045 & 0.045 & 0.045 \\
\hline & 6 & 0.181 & 0.131 & 0.109 & 0.095 & 0.087 & 0.073 & 0.066 & 0.062 & 0.059 & 0.055 & 0.051 & 0.049 & 0.048 & 0.047 & 0.047 & 0.047 & 0.046 & 0.045 & 0.045 & 0.045 \\
\hline & 8 & 0.194 & 0.139 & 0.114 & 0.099 & 0.089 & 0.075 & 0.067 & 0.063 & 0.059 & 0.055 & 0.051 & 0.050 & 0.048 & 0.048 & 0.047 & 0.047 & 0.046 & 0.046 & 0.045 & 0.045 \\
\hline & 10 & 0.207 & 0.145 & 0.118 & 0.102 & 0.091 & 0.076 & 0.068 & 0.063 & 0.059 & 0.056 & 0.052 & 0.050 & 0.049 & 0.048 & 0.047 & 0.047 & 0.046 & 0.046 & 0.046 & 0.045 \\
\hline & 12 & 0.217 & 0.151 & 0.122 & 0.105 & 0.094 & 0.078 & 0.069 & 0.064 & 0.060 & 0.056 & 0.052 & 0.050 & 0.049 & 0.048 & 0.048 & 0.047 & 0.046 & 0.046 & 0.046 & 0.045 \\
\hline & 14 & 0.226 & 0.155 & 0.124 & 0.107 & 0.095 & 0.078 & 0.069 & 0.064 & 0.060 & 0.056 & 0.052 & 0.050 & 0.049 & 0.048 & 0.048 & 0.047 & 0.046 & 0.046 & 0.046 & 0.045 \\
\hline & 16 & 0.234 & 0.159 & 0.127 & 0.109 & 0.097 & 0.079 & 0.070 & 0.064 & 0.061 & 0.056 & 0.052 & 0.050 & 0.049 & 0.048 & 0.047 & 0.047 & 0.046 & 0.046 & 0.046 & 0.045 \\
\hline & 20 & 0.248 & 0.166 & 0.132 & 0.112 & 0.099 & 0.081 & 0.070 & 0.065 & 0.062 & 0.056 & 0.052 & 0.050 & 0.049 & 0.048 & 0.048 & 0.047 & 0.047 & 0.046 & 0.046 & 0.045 \\
\hline & 25 & 0.263 & 0.173 & 0.135 & 0.114 & 0.100 & 0.082 & 0.072 & 0.066 & 0.062 & 0.057 & 0.053 & 0.050 & 0.049 & 0.048 & 0.048 & 0.047 & 0.047 & 0.046 & 0.046 & 0.046 \\
\hline & 32 & 0.279 & 0.180 & 0.140 & 0.118 & 0.103 & 0.082 & 0.072 & 0.066 & 0.062 & 0.057 & 0.053 & 0.050 & 0.049 & 0.049 & 0.048 & 0.048 & 0.047 & 0.047 & 0.046 & 0.046 \\
\hline & 50 & 0.308 & 0.194 & 0.148 & 0.122 & 0.106 & 0.084 & 0.074 & 0.067 & 0.063 & 0.058 & 0.053 & 0.051 & 0.050 & 0.049 & 0.048 & 0.048 & 0.047 & 0.047 & 0.046 & 0.046 \\
\hline \multirow{11}{*}{30} & 4 & 0.231 & 0.175 & 0.149 & 0.133 & 0.122 & 0.105 & 0.095 & 0.088 & 0.083 & 0.077 & 0.071 & 0.067 & 0.066 & 0.064 & 0.063 & 0.063 & 0.062 & 0.061 & 0.060 & 0.060 \\
\hline & 6 & 0.259 & 0.191 & 0.160 & 0.142 & 0.128 & 0.109 & 0.097 & 0.090 & 0.085 & 0.078 & 0.071 & 0.068 & 0.066 & 0.065 & 0.064 & 0.063 & 0.062 & 0.061 & 0.061 & 0.060 \\
\hline & 8 & 0.282 & 0.204 & 0.169 & 0.148 & 0.134 & 0.112 & 0.100 & 0.092 & 0.086 & 0.079 & 0.072 & 0.069 & 0.067 & 0.065 & 0.064 & 0.064 & 0.063 & 0.062 & 0.061 & 0.061 \\
\hline & 10 & 0.301 & 0.216 & 0.176 & 0.154 & 0.138 & 0.115 & 0.102 & 0.093 & 0.087 & 0.080 & 0.072 & 0.069 & 0.067 & 0.066 & 0.065 & 0.064 & 0.063 & 0.062 & 0.061 & 0.061 \\
\hline & 12 & 0.318 & 0.224 & 0.183 & 0.158 & 0.142 & 0.116 & 0.103 & 0.094 & 0.088 & 0.081 & 0.073 & 0.069 & 0.067 & 0.066 & 0.065 & 0.064 & 0.063 & 0.062 & 0.061 & 0.061 \\
\hline & 14 & 0.334 & 0.232 & 0.188 & 0.162 & 0.145 & 0.119 & 0.104 & 0.095 & 0.089 & 0.081 & 0.073 & 0.069 & 0.068 & 0.066 & 0.065 & 0.064 & 0.063 & 0.062 & 0.062 & 0.061 \\
\hline & 16 & 0.346 & 0.240 & 0.193 & 0.166 & 0.147 & 0.120 & 0.105 & 0.096 & 0.089 & 0.081 & 0.074 & 0.070 & 0.068 & 0.066 & 0.065 & 0.064 & 0.063 & 0.062 & 0.062 & 0.061 \\
\hline & 20 & 0.370 & 0.251 & 0.201 & 0.171 & 0.151 & 0.123 & 0.106 & 0.097 & 0.090 & 0.082 & 0.074 & 0.070 & 0.068 & 0.066 & 0.065 & 0.065 & 0.063 & 0.063 & 0.062 & 0.062 \\
\hline & 25 & 0.395 & 0.265 & 0.209 & 0.177 & 0.155 & 0.125 & 0.108 & 0.098 & 0.091 & 0.083 & 0.074 & 0.070 & 0.068 & 0.067 & 0.066 & 0.065 & 0.064 & 0.063 & 0.062 & 0.062 \\
\hline & 32 & 0.423 & 0.280 & 0.218 & 0.184 & 0.161 & 0.128 & 0.110 & 0.100 & 0.092 & 0.083 & 0.075 & 0.071 & 0.069 & 0.067 & 0.066 & 0.065 & 0.064 & 0.063 & 0.062 & 0.062 \\
\hline & 50 & 0.477 & 0.306 & 0.235 & 0.195 & 0.169 & 0.133 & 0.113 & 0.102 & 0.094 & 0.084 & 0.076 & 0.072 & 0.069 & 0.068 & 0.067 & 0.066 & 0.064 & 0.064 & 0.063 & 0.063 \\
\hline \multirow{2}{*}{40} & 4 & 0.317 & 0.242 & 0.208 & 0.188 & 0.173 & 0.149 & 0.135 & 0.125 & 0.118 & 0.108 & 0.097 & 0.092 & 0.089 & 0.087 & 0.085 & 0.084 & 0.082 & 0.081 & 0.080 & 0.079 \\
\hline & 6 & 0.359 & 0.267 & 0.227 & 0.201 & 0.185 & 0.157 & 0.141 & 0.129 & 0.121 & 0.110 & 0.099 & 0.093 & 0.090 & 0.088 & 0.086 & 0.085 & 0.083 & 0.082 & 0.081 & 0.080 \\
\hline
\end{tabular}




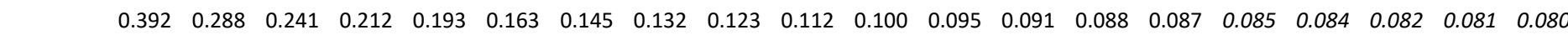
$\begin{array}{llllllllllllllllllllll}0.421 & 0.305 & 0.253 & 0.221 & 0.201 & 0.167 & 0.148 & 0.135 & 0.126 & 0.114 & 0.101 & 0.095 & 0.092 & 0.089 & 0.087 & 0.086 & 0.084 & 0.083 & 0.081 & 0.081 & & \end{array}$ $\begin{array}{llllllllllllllllllll}0.445 & 0.319 & 0.263 & 0.229 & 0.206 & 0.171 & 0.150 & 0.137 & 0.127 & 0.115 & 0.102 & 0.095 & 0.092 & 0.090 & 0.088 & 0.086 & 0.084 & 0.083 & 0.082 & 0.081\end{array}$ $\begin{array}{llllllllllllllllllll}0.468 & 0.332 & 0.272 & 0.236 & 0.211 & 0.175 & 0.152 & 0.139 & 0.129 & 0.116 & 0.103 & 0.096 & 0.092 & 0.090 & 0.088 & 0.087 & 0.085 & 0.083 & 0.082 & 0.081\end{array}$ $\begin{array}{llllllllllllllllllll}0.488 & 0.344 & 0.281 & 0.242 & 0.216 & 0.177 & 0.155 & 0.140 & 0.130 & 0.117 & 0.103 & 0.097 & 0.093 & 0.090 & 0.088 & 0.087 & 0.085 & 0.084 & 0.083 & 0.081\end{array}$ $\begin{array}{llllllllllllllllllll}0.525 & 0.364 & 0.294 & 0.252 & 0.224 & 0.182 & 0.158 & 0.142 & 0.132 & 0.118 & 0.104 & 0.097 & 0.093 & 0.091 & 0.089 & 0.087 & 0.085 & 0.084 & 0.083 & 0.082\end{array}$ $\begin{array}{llllllllllllllllllllll}0.563 & 0.386 & 0.309 & 0.263 & 0.233 & 0.187 & 0.162 & 0.145 & 0.134 & 0.119 & 0.105 & 0.098 & 0.094 & 0.091 & 0.089 & 0.088 & 0.086 & 0.084 & 0.083 & 0.082\end{array}$

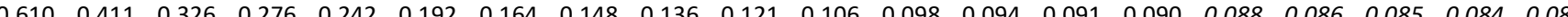

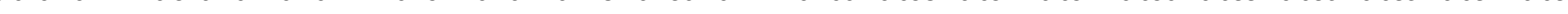
\begin{tabular}{llllllllllllllllllll}
0.699 & 0.458 & 0.356 & 0.297 & 0.258 & 0.201 & 0.172 & 0.153 & 0.139 & 0.123 & 0.107 & 0.100 & 0.095 & 0.092 & 0.091 & 0.089 & 0.087 & 0.085 & 0.084 & 0.083 \\
\hline 0.402 & 0.309 & 0.268 & 0.242 & 0.224 & 0.195 & 0.177 & 0.164 & 0.154 & 0.141 & 0.126 & 0.118 & 0.113 & 0.110 & 0.107 & 0.105 & 0.102 & 0.100 & 0.099 & 0.097
\end{tabular} $\begin{array}{llllllllllllllllllllll}0.402 & 0.309 & 0.268 & 0.242 & 0.224 & 0.195 & 0.177 & 0.164 & 0.154 & 0.141 & 0.126 & 0.118 & 0.113 & 0.110 & 0.107 & 0.105 & 0.102 & 0.100 & 0.099 & 0.097 \\ 0.458 & 0.344 & 0.293 & 0.262 & 0.241 & 0.207 & 0.185 & 0.170 & 0.160 & 0.145 & 0.128 & 0.120 & 0.115 & 0.111 & 0.109 & 0.106 & 0.104 & 0.102 & 0.100 & 0.099\end{array}$ $\begin{array}{llllllllllllllllllll}0.503 & 0.372 & 0.314 & 0.279 & 0.254 & 0.215 & 0.192 & 0.175 & 0.164 & 0.148 & 0.130 & 0.122 & 0.116 & 0.112 & 0.110 & 0.108 & 0.105 & 0.103 & 0.101 & 0.099\end{array}$ $\begin{array}{llllllllllllllllllll}0.540 & 0.396 & 0.331 & 0.291 & 0.264 & 0.222 & 0.197 & 0.179 & 0.167 & 0.150 & 0.132 & 0.123 & 0.117 & 0.113 & 0.110 & 0.108 & 0.105 & 0.103 & 0.102 & 0.100\end{array}$ $\begin{array}{llllllllllllllllllll}0.575 & 0.416 & 0.345 & 0.302 & 0.274 & 0.228 & 0.201 & 0.183 & 0.170 & 0.152 & 0.133 & 0.124 & 0.118 & 0.114 & 0.111 & 0.109 & 0.106 & 0.104 & 0.102 & 0.101\end{array}$ $\begin{array}{lllllllllllllllllllllll}0.605 & 0.434 & 0.358 & 0.313 & 0.282 & 0.233 & 0.205 & 0.186 & 0.172 & 0.154 & 0.134 & 0.125 & 0.118 & 0.115 & 0.112 & 0.110 & 0.106 & 0.104 & 0.103 & 0.101\end{array}$

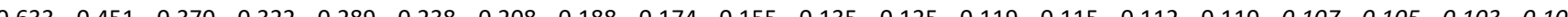

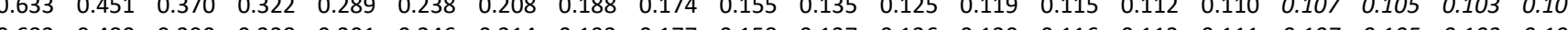
$\begin{array}{llllllllllllllllllllllll}0.682 & 0.480 & 0.390 & 0.338 & 0.301 & 0.246 & 0.214 & 0.193 & 0.177 & 0.158 & 0.137 & 0.126 & 0.120 & 0.116 & 0.113 & 0.111 & 0.107 & 0.105 & 0.103 & 0.102\end{array}$ $\begin{array}{llllllllllllllllllllllllll}0.736 & 0.510 & 0.413 & 0.355 & 0.315 & 0.254 & 0.219 & 0.197 & 0.181 & 0.160 & 0.138 & 0.127 & 0.121 & 0.117 & 0.114 & 0.112 & 0.108 & 0.106 & 0.104 & 0.103\end{array}$ $\begin{array}{llllllllllllllllllll}0.801 & 0.547 & 0.438 & 0.373 & 0.329 & 0.263 & 0.226 & 0.201 & 0.184 & 0.162 & 0.139 & 0.128 & 0.122 & 0.118 & 0.114 & 0.112 & 0.109 & 0.107 & 0.105 & 0.103\end{array}$ \begin{tabular}{llllllllllllllllllll}
0.929 & 0.618 & 0.485 & 0.408 & 0.356 & 0.279 & 0.237 & 0.209 & 0.190 & 0.167 & 0.142 & 0.130 & 0.123 & 0.119 & 0.116 & 0.113 & 0.110 & 0.108 & 0.106 & 0.104 \\
\hline
\end{tabular} $\begin{array}{llllllllllllllllllllll}0.485 & 0.376 & 0.326 & 0.296 & 0.275 & 0.240 & 0.218 & 0.203 & 0.191 & 0.174 & 0.155 & 0.144 & 0.137 & 0.133 & 0.129 & 0.127 & 0.123 & 0.120 & 0.118 & 0.116\end{array}$ $\begin{array}{llllllllllllllllllll}0.556 & 0.420 & 0.360 & 0.323 & 0.297 & 0.256 & 0.230 & 0.213 & 0.199 & 0.180 & 0.159 & 0.147 & 0.140 & 0.135 & 0.131 & 0.129 & 0.125 & 0.122 & 0.119 & 0.117\end{array}$ $\begin{array}{lllllllllllllllllllll}0.612 & 0.456 & 0.386 & 0.344 & 0.315 & 0.268 & 0.240 & 0.220 & 0.205 & 0.185 & 0.162 & 0.150 & 0.142 & 0.137 & 0.133 & 0.130 & 0.126 & 0.123 & 0.121 & 0.119\end{array}$ $\begin{array}{llllllllllllllllllll}0.661 & 0.487 & 0.409 & 0.362 & 0.329 & 0.279 & 0.247 & 0.226 & 0.210 & 0.188 & 0.164 & 0.151 & 0.143 & 0.138 & 0.134 & 0.131 & 0.127 & 0.124 & 0.122 & 0.119\end{array}$ $\begin{array}{lllllllllllllllllllllll}0.127 & 0.124 & 0.122 & 0.119\end{array}$ $\begin{array}{llllllllllllllllllllllllll}0.704 & 0.513 & 0.428 & 0.377 & 0.342 & 0.287 & 0.253 & 0.231 & 0.214 & 0.191 & 0.166 & 0.153 & 0.145 & 0.139 & 0.135 & 0.132 & 0.128 & 0.125 & 0.122 & 0.120\end{array}$ $\begin{array}{lllllllllllllllllllll}0.742 & 0.536 & 0.445 & 0.391 & 0.353 & 0.294 & 0.259 & 0.235 & 0.218 & 0.194 & 0.168 & 0.154 & 0.146 & 0.140 & 0.136 & 0.133 & 0.129 & 0.125 & 0.123 & 0.121 & \\ 0.778 & 0.559 & 0.461 & 0.403 & 0.363 & 0.301 & 0.263 & 0.239 & 0.221 & 0.196 & 0.169 & 0.155 & 0.147 & 0.141 & 0.137 & 0.134 & 0.129 & 0.126 & 0.123 & 0.121\end{array}$ $\begin{array}{lllllllllllllllllllll}0.778 & 0.559 & 0.461 & 0.403 & 0.363 & 0.301 & 0.263 & 0.239 & 0.221 & 0.196 & 0.169 & 0.155 & 0.147 & 0.141 & 0.137 & 0.134 & 0.129 & 0.126 & 0.123 & 0.121\end{array}$ $\begin{array}{llllllllllllllllllll}0.841 & 0.597 & 0.489 & 0.424 & 0.380 & 0.312 & 0.272 & 0.245 & 0.225 & 0.199 & 0.171 & 0.157 & 0.148 & 0.142 & 0.138 & 0.135 & 0.130 & 0.127 & 0.124 & 0.122\end{array}$ $\begin{array}{lllllllllllllllllllll}0.910 & 0.639 & 0.518 & 0.447 & 0.398 & 0.323 & 0.280 & 0.252 & 0.230 & 0.203 & 0.174 & 0.158 & 0.149 & 0.143 & 0.139 & 0.136 & 0.131 & 0.128 & 0.125 & 0.123\end{array}$ $\begin{array}{llllllllllllllllllll}0.992 & 0.687 & 0.552 & 0.473 & 0.419 & 0.337 & 0.290 & 0.258 & 0.236 & 0.207 & 0.176 & 0.160 & 0.151 & 0.144 & 0.140 & 0.137 & 0.132 & 0.129 & 0.126 & 0.124\end{array}$ \begin{tabular}{llllllllllllllllllll}
1.161 & 0.783 & 0.618 & 0.523 & 0.459 & 0.362 & 0.307 & 0.271 & 0.246 & 0.213 & 0.180 & 0.163 & 0.153 & 0.147 & 0.142 & 0.139 & 0.134 & 0.130 & 0.128 & 0.126 \\
\hline
\end{tabular} $\begin{array}{llllllllllllllllllllll}0.568 & 0.441 & 0.383 & 0.349 & 0.325 & 0.285 & 0.260 & 0.242 & 0.229 & 0.209 & 0.185 & 0.171 & 0.162 & 0.156 & 0.152 & 0.148 & 0.143 & 0.139 & 0.136 & 0.134\end{array}$ $\begin{array}{lllllllllllllllllllllllll}0.58 & 0.441 & 0.383 & 0.349 & 0.325 & 0.285 & 0.260 & 0.242 & 0.229 & 0.209 & 0.185 & 0.171 & 0.162 & 0.156 & 0.152 & 0.148 & 0.143 & 0.139 & 0.136 & 0.134 \\ 0.453 & 0.496 & 0.425 & 0.383 & 0.353 & 0.306 & 0.276 & 0.255 & 0.240 & 0.217 & 0.190 & 0.176 & 0.166 & 0.160 & 0.155 & 0.151 & 0.146 & 0.142 & 0.1388 & 0.136\end{array}$ $\begin{array}{llllllllllllllllllllll}0.722 & 0.541 & 0.459 & 0.410 & 0.376 & 0.322 & 0.289 & 0.266 & 0.248 & 0.223 & 0.195 & 0.179 & 0.169 & 0.162 & 0.157 & 0.153 & 0.148 & 0.143 & 0.140 & 0.137\end{array}$ $\begin{array}{llllllllllllllllllll}0.781 & 0.579 & 0.487 & 0.432 & 0.395 & 0.335 & 0.299 & 0.274 & 0.255 & 0.228 & 0.198 & 0.181 & 0.171 & 0.164 & 0.159 & 0.155 & 0.149 & 0.145 & 0.141 & 0.139\end{array}$ $\begin{array}{llllllllllllllllllll}0.833 & 0.612 & 0.512 & 0.452 & 0.411 & 0.346 & 0.307 & 0.280 & 0.260 & 0.232 & 0.201 & 0.183 & 0.173 & 0.165 & 0.160 & 0.156 & 0.150 & 0.146 & 0.142 & 0.140\end{array}$ $\begin{array}{llllllllllllllllllll}0.881 & 0.640 & 0.534 & 0.469 & 0.425 & 0.356 & 0.315 & 0.286 & 0.265 & 0.236 & 0.203 & 0.185 & 0.174 & 0.167 & 0.161 & 0.157 & 0.151 & 0.147 & 0.143 & 0.141\end{array}$ $\begin{array}{llllllllllllllllllll}0.923 & 0.668 & 0.554 & 0.485 & 0.438 & 0.365 & 0.321 & 0.291 & 0.269 & 0.239 & 0.205 & 0.187 & 0.175 & 0.168 & 0.162 & 0.158 & 0.152 & 0.148 & 0.144 & 0.141\end{array}$ $\begin{array}{llllllllllllllllllll}1.001 & 0.716 & 0.589 & 0.514 & 0.461 & 0.380 & 0.332 & 0.300 & 0.276 & 0.244 & 0.208 & 0.189 & 0.177 & 0.169 & 0.164 & 0.159 & 0.153 & 0.149 & 0.145 & 0.143\end{array}$ $\begin{array}{llllllllllllllllllll}1.086 & 0.767 & 0.626 & 0.542 & 0.485 & 0.396 & 0.344 & 0.308 & 0.284 & 0.249 & 0.211 & 0.191 & 0.179 & 0.171 & 0.165 & 0.161 & 0.155 & 0.150 & 0.147 & 0.144\end{array}$ $\begin{array}{llllllllllllllllllllll}1.186 & 0.828 & 0.670 & 0.576 & 0.512 & 0.414 & 0.357 & 0.319 & 0.292 & 0.255 & 0.215 & 0.194 & 0.181 & 0.173 & 0.167 & 0.162 & 0.156 & 0.151 & 0.148 & 0.145\end{array}$ \begin{tabular}{lllllllllllllllllllllll}
1.395 & 0.951 & 0.756 & 0.644 & 0.566 & 0.448 & 0.381 & 0.337 & 0.306 & 0.265 & 0.221 & 0.198 & 0.185 & 0.176 & 0.170 & 0.165 & 0.158 & 0.154 & 0.150 & 0.147 \\
\hline
\end{tabular} 


\section{Acknowledgements}

DIAMOND is a collaborative R\&D project supported by the French government FUI program, Direction Générale des Entreprises, BPI France and PACA regional council, and accredited by four competitiveness clusters : SAFE, Mer Méditerranée, Nuclear Valley, Alpha RLH.

\section{References}

[1] W. Morris, A. Vico, M. Vazquez, S.R. de Sanchez, Corrosion of reinforcing steel evaluated by means of concrete resistivity measurements, Corros. Sci. 44 (2002) 81-99. doi:10.1016/S0010-938X(01)00033-6.

[2] W.J. McCarter, H.M. Taha, B. Suryanto, G. Starrs, Two-point concrete resistivity measurements: interfacial phenomena at the electrode-concrete contact zone, Meas. Sci. Technol. 26 (2015) 085007. doi:10.1088/0957-0233/26/8/085007.

[3] M.G. Alexander, Y. Ballim, K. Stanish, A framework for use of durability indexes in performance-based design and specifications for reinforced concrete structures, Mater. Struct. 41 (2008) 921-936. doi:10.1617/s11527-007-9295-0.

[4] K. Reichling, M. Raupach, N. Klitzsch, Determination of the distribution of electrical resistivity in reinforced concrete structures using electrical resistivity tomography: ERT on reinforced concrete, Mater. Corros. 66 (2015) 763-771. doi:10.1002/maco.201407763.

[5] R.B. Polder, Test methods for on site measurement of resistivity of concrete - a RILEM TC-154 technical recommendation, Constr. Build. Mater. 15 (2001) 125-131. doi:10.1016/S0950-0618(00)00061-1.

[6] H. Yildirim, T. Ilica, O. Sengul, Effect of cement type on the resistance of concrete against chloride penetration, Constr. Build. Mater. 25 (2011) 1282-1288. doi:10.1016/j.conbuildmat.2010.09.023.

[7] A.J. Garzon, J. Sanchez, C. Andrade, N. Rebolledo, E. Menéndez, J. Fullea, Modification of four point method to measure the concrete electrical resistivity in presence of reinforcing bars, Cem. Concr. Compos. 53 (2014) 249-257. doi:10.1016/j.cemconcomp.2014.07.013.

[8] DIAMOND project, Proj. Diam. - Diagn. Corros. Béton Armé - Sonde Captae. (2017). https://www.projet-diamond.com (accessed May 11, 2017).

[9] C.J. Newton, J.M. Sykes, A galvanostatic pulse technique for investigation of steel corrosion in concrete, Corros. Sci. 28 (1988) 1051-1074. doi:10.1016/0010938X(88)90101-1.

[10] B. Elsener, O. Klinghoffer, T. Frolund, E. Rislund, Y. Schiegg, H. Böhni, Assessment of reinforcement corrosion by means of galvanostatic pulse technique, in: Norway, 1997.

[11] P.V. Nygaard, Non-destructive elecrochemical monitoring of reinforcement corrosion, Technical University of Denmark (DTU), 2009.

[12] P.V. Nygaard, M.R. Geiker, B. Elsener, Corrosion rate of steel in concrete: evaluation of confinement techniques for on-site corrosion rate measurements, Mater. Struct. 42 (2009) 1059-1076. doi:10.1617/s11527-008-9443-1.

[13] P.V. Nygaard, M.R. Geiker, Measuring the corrosion rate of steel in concrete - effect of measurement technique, polarisation time and current, Mater. Corros. 63 (2012) 200214. doi:10.1002/maco.201005792. 
[14] C. Andrade, C. Alonso, On-site measurements of corrosion rate of reinforcements, Constr. Build. Mater. 15 (2001) 141-145. doi:10.1016/S0950-0618(00)00063-5.

[15] C. Andrade, C. Alonso, Test methods for on-site corrosion rate measurement of steel reinforcement in concrete by means of the polarization resistance method, Mater. Struct. 37 (2004) 623-643. doi:10.1007/BF02483292.

[16] J. Newman, Resistance for Flow of Current to a Disk, J. Electrochem. Soc. 113 (1966) 501-502. doi:10.1149/1.2424003.

[17] S. Feliu, C. Andrade, J.A. González, C. Alonso, A new method for in-situ measurement of electrical resistivity of reinforced concrete, Mater. Struct. 29 (1996) 362-365. doi:10.1007/BF02486344.

[18] H. Layssi, P. Ghods, A.R. Alizadeh, M. Salehi, Electrical Resistivity of Concrete, Concr. Int. 37 (2015) 41-46.

[19] F. Wenner, A method of measuring earth resistivity, Govt. Print. Off., 1916.

[20] J. Sanchez, C. Andrade, J. Torres, N. Rebolledo, J. Fullea, Determination of reinforced concrete durability with on-site resistivity measurements, Mater. Struct. 50 (2017) 41. doi:10.1617/s11527-016-0884-7.

[21] F. Presuel-Moreno, Y. Liu, Y.-Y. Wu, Numerical modeling of the effects of rebar presence and/or multilayered concrete resistivity on the apparent resistivity measured via the Wenner method, Constr. Build. Mater. 48 (2013) 16-25. doi:10.1016/j.conbuildmat.2013.06.053.

[22] M. Salehi, P. Ghods, O.B. Isgor, Numerical investigation of the role of embedded reinforcement mesh on electrical resistivity measurements of concrete using the Wenner probe technique, Mater. Struct. 49 (2016) 301-316. doi:10.1617/s11527-014-0498-x.

[23] M.E. Mitzithra, F. Deby, J.P. Balayssac, J. Salin, Proposal for an alternative operative method for determination of polarisation resistance for the quantitative evaluation of corrosion of reinforcing steel in concrete cooling towers, Nucl. Eng. Des. 288 (2015) 42-55. doi:10.1016/j.nucengdes.2015.03.018.

[24] M.E. Mitzithra, Detection of corrosion of reinforced concrete on cooling towers of energy production sites, PhD Thesis, University of Toulouse III - Paul Sabatier, 2013. http://thesesups.ups-tlse.fr/2135/ (accessed August 29, 2016).

[25] M. Al-Soudani, Diagnosis of Reinforced Concrete Structures in Civil Engineering by GPR Technology: Development of Alternate Methods for Precise Geometric Recognition, PhD Thesis, LMDC Toulouse, France, 2017.

[26] J. Warkus, M. Raupach, J. Gulikers, Numerical modelling of corrosion - Theoretical backgrounds -, Mater. Corros. 57 (2006) 614-617. doi:10.1002/maco.200603992.

[27] U. Angst, M. Büchler, On the applicability of the Stern-Geary relationship to determine instantaneous corrosion rates in macro-cell corrosion, Mater. Corros. 66 (2015) 10171028. doi:10.1002/maco.201407997.

[28] S. Laurens, P. Hénocq, N. Rouleau, F. Deby, E. Samson, J. Marchand, B. Bissonnette, Steady-state polarization response of chloride-induced macrocell corrosion systems in steel reinforced concrete - numerical and experimental investigations, Cem. Concr. Res. 79 (2016) 272-290. doi:10.1016/j.cemconres.2015.09.021.

[29] S. Feliu, J.A. González, J.M. Miranda, V. Feliu, Possibilities and problems of in situ techniques for measuring steel corrosion rates in large reinforced concrete structures, Corros. Sci. 47 (2005) 217-238. doi:10.1016/j.corsci.2004.04.011.

[30] J.A. González, J.M. Miranda, S. Feliu, Considerations on reproducibility of potential and corrosion rate measurements in reinforced concrete, Corros. Sci. 46 (2004) 2467-2485. doi:10.1016/j.corsci.2004.02.003. 
[31] M.G. Sohail, S. Laurens, F. Deby, J.P. Balayssac, Significance of macrocell corrosion of reinforcing steel in partially carbonated concrete: numerical and experimental investigation, Mater. Struct. 48 (2013) 217-233. doi:10.1617/s11527-013-0178-2.

\section{Table of contents}

A new concrete resistivity assessment methodology is proposed. It is based on measuring the instantaneous ohmic drop at the beginning of the polarization. The problem is numerically modelled in Comsol and the method is then validated experimentally. The geometrical factor depends on CE diameter, concrete cover and rebar diameter but is independent of rebar spacing framework. 


\section{List of figures}

Figure 1. Principles of resistivity measurements. Two-electrode method (a); Wenner probe (b); oneelectrode method (c). 7

Figure 2. Equivalent electrical circuit (a), absolute potential evolution without polarization (b), with

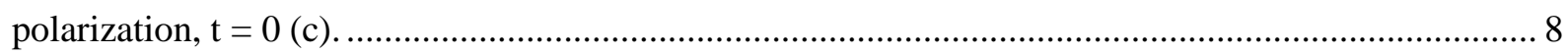

Figure 3. DIAMOND probe: schematic layout and side view photo. ................................................ 9

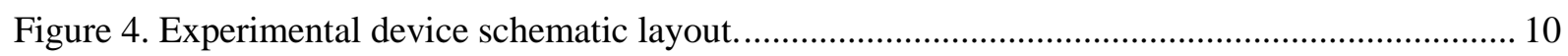

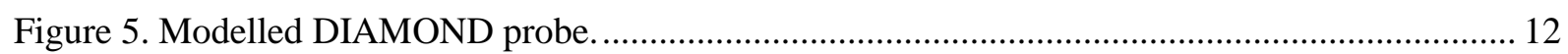

Figure 6. Modelled geometry. $D=32 \mathrm{~mm}$ and $c=50 \mathrm{~mm}$. Single bar (a), multiple bar with spacing $s=80 \mathrm{~mm}(\mathrm{~b})$. 12

Figure 7. Electrical potential on the surface of the studied domain for a concrete cover $c$ of $60 \mathrm{~mm}$, a rebar having a diameter $D$ of $32 \mathrm{~mm}$, and a concrete resistivity $\rho$ of $1000 \Omega . \mathrm{m}$.

Figure 8. Electrical potential along $\mathbf{Z}$ axis for two concrete covers (10 and $60 \mathrm{~mm})$ and two rebar diameters (8 and $32 \mathrm{~mm}) ; \rho=1000 \Omega . \mathrm{m} ; D_{C E}=22 \mathrm{~mm}(\mathrm{a}), D_{C E}=60 \mathrm{~mm}$ (b).

Figure 9. Electrical potential along $\mathbf{z}$ axis for two concrete covers (10 and $60 \mathrm{~mm})$ and two rebar diameters ( 8 and $32 \mathrm{~mm}$ ); $\rho=100 \Omega . \mathrm{m} ; D_{C E}=22 \mathrm{~mm}$.

Figure 10. Concrete resistance $R_{\Omega}[\Omega]$ versus resistivity for two rebar diameters, $8 \mathrm{~mm}$ (dotted lines) and $32 \mathrm{~mm}$ (continuous lines) and two CE diameters, $22 \mathrm{~mm}$ (full markers) and $60 \mathrm{~mm}$ (empty markers)

Figure 11. Geometrical factor $k$ of a single rebar depending on concrete cover for five rebar diameters and Feliu's geometrical factor. Values can be find in appendix.

Figure 12. Resistivity $\rho[\Omega . \mathrm{m}]$, calculated with $k$ factor (Figure 11 (a)) according to the concrete cover for two rebar diameters, $8 \mathrm{~mm}$ (dotted lines) and $32 \mathrm{~mm}$ (continuous lines). Straight lines are true resistivities. Hollow lines are Feliu resistivity $(D=8 \mathrm{~mm}) . \rho=14,40$ and $100 \Omega . \mathrm{m}(\mathrm{a}), \rho=250,500$ and $1000 \Omega . m(b)$ 20 
Figure 13. Current line distribution for concrete cover of $50 \mathrm{~mm}$ and rebar diameter of $32 \mathrm{~mm} . s=\infty$ (a), $s=240 \mathrm{~mm}$ (b), $s=80 \mathrm{~mm}$ (c). $D_{C E}=22 \mathrm{~mm}$. Red (zone $1-4 \mathrm{~cm}$ area), black (zone 2 - the rest of the primary bar), blue (zone 3 - other bar(s)).

Figure 14. Current distribution in the three zones of the rebars according to concrete cover for two rebar diameters, $8 \mathrm{~mm}$ (green lines) and $32 \mathrm{~mm}$ (black lines). $D_{C E}=22 \mathrm{~mm} . s=\infty$ (a), $s=240 \mathrm{~mm}$ (b), $s=80 \mathrm{~mm}(\mathrm{c})$ 25

Figure 15. Current distributions according to concrete cover and rebar spacing. Rebar diameter $=$ $32 \mathrm{~mm} . D_{C E}=22 \mathrm{~mm}$. Zone 1 (a), zone 2 (b), zone 3 (c). 26

Figure 16. Ohmic drop $\Delta E_{\Omega}$ in concrete according to concrete cover for two rebar diameters ( 8 and 32 $\mathrm{mm})$ and three rebar spacings $(\infty, 240$ and $80 \mathrm{~mm}) ; \rho=1000 \Omega . \mathrm{m}$. 27

\section{List of table}

Table 1. Current distribution in the three zones for $50 \mathrm{~mm}$ concrete cover and three spacing factors $(\infty, 240$ and $80 \mathrm{~mm})$ for a total of 2000 current lines. $\mathrm{D}=32 \mathrm{~mm}$. 